\title{
Common polygenic variations for psychiatric disorders and cognition in relation to brain morphology in the general pediatric population
}

\section{Short title: Polygenic scores and brain morphology}

Authors: Silvia Alemany *, PhD; Philip R. Jansen, MD, MSc; Ryan L. Muetzel, PhD; Natália Marques, BSc; Hanan El Marroun, MD, PhD; Vincent W.V. Jaddoe, MD, PhD; Tinca J.C. Polderman, PhD; Henning Tiemeier, MD, PhD; Danielle Posthuma, PhD; Tonya White, MD, $\mathrm{PhD}$.

Silvia Alemany is with the Barcelona Institute for Global Health and Universitat Pompeu Fabra (UPF), Barcelona, Spain and with the CIBER Epidemiología y Salud Pública (CIBERESP), Madrid, Spain. Philip R. Jansen, Ryan L.Muetzel, Hanan El Marroun, Henning Tiemeier and Tonya White are with the Department of Child and Adolescent Psychiatry, Erasmus University Medical Center, Rotterdam, the Netherlands. Philip R. Jansen, Hanan El Marroun and Vicent W.V. Jaddoe are also with The Generation R Study Group, Erasmus University Medical Center, Rotterdam, the Netherlands. Philip R. Jansen and Tonya White are also with the Department of Radiology, Erasmus University Medical Center, Rotterdam, the Netherlands. Ryan L. Muetzel and Vicent W.V. Jaddoe are with the Department of Epidemiology, Erasmus University Medical Center, Rotterdam, the Netherlands. Vicent W.V. Jaddoe is also with the Department of Pediatrics, Erasmus University Medical Center, Rotterdam, the Netherlands. Philip R. Jansen, Tinca J.C. Polderman and Danielle Posthuma are with the Department of Complex Trait Genetics, Center for Neurogenomics and Cognitive Research, Amsterdam Neuroscience, VU 
University, Amsterdam, the Netherlands. Danielle Posthuma is also with the Department of Clinical Genetics, VU University Medical Center, Amsterdam, the Netherlands. Henning Tiemeier is also with the Department of Social and Behavioral Science, Harvard TH Chan School of Public Health, Boston, USA. Natália Marques is Instituto de Biofísica e Engenharia Biomédica, Faculdade de Ciências, Universidade de Lisboa, Lisbon, Portugal.

\section{Abstract word count: 231 \\ Manuscript word count: 3803 \\ Number of tables/figures: $0 / 2$ \\ Total number of tables and figures in supplemental material: 5}

*Corresponding author: Silvia Alemany, Barcelona Institute for Global Health (ISGlobal), C. Doctor Aiguader 88, 08003 Barcelona, Spain. Phone: +34 9321473 62. Fax: +34 93214730.2 E-mail: silvia.alemany@isglobal.org

This work was supported by the Sophia Foundation for Scientific Research (SSWO project number: S14-27) and the Netherlands Organization for Health Research and Development (ZonMw) TOP project number 91211021 to T. White. Supercomputing computations were supported by the NWO Physical Sciences Division (Exacte Wetenschappen) and SURFsara (Cartesius computer cluster, www.surfsara.nl). The Generation R Study is conducted by the Erasmus Medical Center in close collaboration with the School of Law and Faculty of Social Sciences of the Erasmus University Rotterdam, the Municipal Health Service Rotterdam area, Rotterdam, the Rotterdam Homecare Foundation, Rotterdam and the Stichting Trombosedienst \& Artsenlaboratorium Rijnmond (STARMDC). S. Alemany is funded by a Sara Borrell 
postdoctoral grant (CD14/00214) from the Instituto de Salud Carlos III. P.R. Jansen is funded by the Sophia Foundation for Scientific Research (SSWO, grant: S14-27).

The authors thank the participants and their parents that contributed to the Generation R Study, and the researchers who were involved in data collection.

Drs. Alemany, Jansen, Muetzel, El Marroun, Jaddoe, Polderman, Tiemeier, Posthuma and White, and Mrs. Marques report no biomedical financial interests or potential conflicts of interest.

\section{Social Media}

New study @JAACAP finds relationships between \#polygenic susceptibility for \#ADHD and cognition and brain morphological differences at caudate and total brain volumes in schoolchildren from @GenerationR_010

\section{Lay Summary}

Our results based on data from schoolchildren participating in the Generation R Study (The Netherlands) suggest that genetic susceptibility for attention-deficit hyperactivity disorder (ADHD) and cognition manifest early in life by influencing brain structure. Interestingly, genetic risk for ADHD was related to smaller caudate nucleus volume, a region previously associated with this disorder. 


\section{ABSTRACT}

Objective: To examine the relationship between polygenic scores (PGS) for five major psychiatric disorders and two cognitive traits with brain MRI morphological measurements in a large population-based sample of children. Additionally, we tested whether differences in brain morphology mediated associations between PGS for psychiatric disorders and related behavioral phenotypes.

Method: The participants included 1,139 children from the Generation R Study assessed at 10 years-of-age with genotype and neuroimaging data available. PGS were calculated for schizophrenia, bipolar disorder, major depression disorder, attention-deficit hyperactivity disorder (ADHD), autism spectrum disorder (ASD), intelligence and educational attainment (EA) using results from the latest genome-wide association studies. Image processing was performed using FreeSurfer to extract cortical and subcortical brain volumes.

Results: Higher genetic susceptibility for ADHD was associated with smaller caudate volume (strongest prior $=0.01: \beta=-0.07, P=0.006$ ). Within boys, mediation analyses estimates suggested found that $11 \%$ of the association between the polygenic score for ADHD and attention problems was mediated by differences in caudate volume $(n=535)$, while mediation was not significant in girls or the entire sample. PGS for EA and intelligence showed positive associations with total brain volume $(\mathrm{TBV})$ (strongest prior $=0.5: \beta=0.14, \mathrm{P}=7.12 \times 10^{-8}$; and $\beta=0.12, \mathrm{P}=6.87 \times 10^{-7}$, respectively).

Conclusions: Our findings indicate that the neurobiological manifestation of polygenic susceptibility for ADHD, EA, and intelligence involve early morphological differences in caudate and total brain volumes in childhood. Furthermore, the genetic risk for ADHD may influence attention problems via the caudate nucleus in boys. 
Keywords: polygenic risk score, neuroimaging, ADHD, educational attainment, intelligence 


\section{INTRODUCTION}

Findings from genome-wide association studies (GWAS) indicate that multiple common genetic variants of small effect contribute to the etiology of psychiatric disorders, implying a highly polygenic architecture. ${ }^{1}$ However, it remains largely unknown how these common genetic variants ultimately contribute to the development of psychiatric symptoms.

Polygenic scores (PGS) are increasingly being used to index individual genetic susceptibility for a given disorder or trait and explore shared genetic influences across phenotypes to improve understanding of disease etiology. ${ }^{2}$ Studies in childhood have shown that the polygenic risk for schizophrenia is associated with lower cognitive abilities, greater social impairments, more behavioral problems, and psychopathology. ${ }^{3-5}$ Interestingly, previous work from our group found that genetic susceptibility for educational attainment (years of schooling) was inversely related to child behavioral problems. ${ }^{4}$ In a large prospective study, polygenic risk for major depressive disorder was shown to be associated with emotional problems in adulthood, but not earlier in life. ${ }^{6}$ Similarly, genetic risk for bipolar disorder has been studied in adult samples. suggesting an association with increased risk for different psychiatric disorders. ${ }^{7}$ Regarding child onset psychiatric disorders, PGS for attention-deficit hyperactivity disorder (ADHD) have been associated with inattentive and hyperactive-impulsive traits, worse educational outcomes and lower IQ in children and adolescents from the general population.,9

Since genetic susceptibility to psychopathology and cognitive function has been linked to behavior, ${ }^{4}$ it could imply that heritable neurobiological mechanisms are at play in the early presentation of symptoms. Within this context, it is well established that brain morphology during development is highly influenced by genetic factors. ${ }^{10}$ Furthermore, widespread morphological brain abnormalities have been associated with the pathophysiology of major 
psychiatric disorders. ${ }^{11-15}$ Although both genetic and environmental factors can account for these brain abnormalities, we expect that genetic susceptibility for psychiatric disorders are associated with variations in brain morphology. Indeed, several studies report relationships between PGS for psychiatric disorders and structural brain MRI measurements in adults using medium to large sample sizes within the context of the field of imaging genetics. ${ }^{16-19}$ Higher genetic risk for schizophrenia was related to total brain volume in both patients with schizophrenia $(\mathrm{N}=152)$ and controls ( $\mathrm{N}=142),{ }^{16}$ although this finding was not replicated using two large general populationbased samples $(\mathrm{N}=763$ and $\mathrm{N}=707) .{ }^{17}$ Other studies in healthy populations have related polygenic risk for both schizophrenia and bipolar disorder with reduced globus pallidus and amygdala volumes ( $\mathrm{N}=274) .{ }^{18}$ However, one of the largest studies to date did not find evidence for associations between polygenic risk for schizophrenia, bipolar disorder or major depression and subcortical brain volumes using data from the UK Biobank study ( $\mathrm{N}=978) \cdot{ }^{19}$ Furthermore, to our knowledge, no study has yet been conducted in a pediatric MRI sample representative of the general population. Thus, whether associations of polygenic susceptibility for major psychiatric disorders and brain morphology are present earlier in life is largely unclear. Since ASD and ADHD are child-onset psychiatric disorders, the study of polygenic risk for these traits in pediatric samples is particularly relevant. To date, this has been hampered by the lack of largescale imaging studies in children that include genetic data.

Within this backdrop, it was the goal of our study to examine the association between polygenic susceptibility for five psychiatric disorders and two cognitive outcomes with global and subcortical brain volumes in a large population-based sample of school-age children. As a secondary aim, we investigated the potential mediating role of brain morphological variation on 
associations between polygenic scores for psychiatric disorders and related behavioral phenotypes.

We hypothesized that polygenic susceptibility for schizophrenia, bipolar disorder, major depression disorder, autism spectrum disorders and ADHD are associated with brain morphological characteristics that overlap with brain abnormalities consistently reported in patients affected by these disorders. Regarding EA and intelligence, we hypothesized that PGS for these traits positively associated with global brain morphology measures.

\section{METHOD}

\section{Study population}

Participants were drawn from the Generation R Study, an ongoing population-based cohort aimed to study many domains of child development. ${ }^{20}$ As part of the cohort's magnetic resonance imaging (MRI) study, 3,992 children were scanned between March 2013 and November 2015 corresponding to the 9-to-11 years-of-age Generation R visit. ${ }^{21}$ Of these children, 3,937 had images that were reconstructed using FreeSurfer (version 6.0 [http://surfer.nmr.mgh.harvard.edu/]). One-hundred thirty-one children were excluded due to either the use of a different sequence $(n=22)$, dental braces $(n=87)$, and the presence of incidental findings $(n=22) .{ }^{22}$ From the remaining 3,806, 620 scans were excluded due to data rated as unusable after visual inspection of segmentation quality. This left 3,186 children with good quality MRI data. Of these, genotype data was available for 1,189 children with European ancestry. Finally, relatedness and genotype quality resulted in an additional exclusion of 50 children. Thus, the final sample included 1,139 participants (see flowchart in Figure S1, available online). 
The study protocol was approved by the Medical Ethics Committee of the Erasmus Medical Centre. Written informed consent was obtained from the legal representatives of all participants.

MRI

To familiarize participants with the MRI scanning environment, all children underwent a mock scanning session. Structural MRI scans were obtained on a 3-Tesla scanner (Discovery MR750W, GE Worldwide, Milwaukee, USA). Whole-brain high-resolution T1-weighted inversion recovery fast spoiled gradient recalled (IR-FSPGR) sequences were obtained using an 8-channel head coil. The scan parameters were: $\mathrm{TR}=8.77 \mathrm{~ms}$, TE $=3.4 \mathrm{~ms}$, TI=600ms, flip angle $=10^{\circ}$, field of view $=220 \mathrm{~mm} \times 220 \mathrm{~mm}$, acquisition matrix $=220 \times 220$, asset acceleration factor $=2, \mathrm{~b}=900 \mathrm{~s} / \mathrm{mm}^{2}, 230$ contiguous slices with a thickness of $1.0 \mathrm{~mm}$, and in-plane resolution $=1.0 \times 1.0 \mathrm{~mm}$. Further details on the design and protocol of the Generation $\mathrm{R}$ cohort’s MRI study can be found elsewhere. ${ }^{21}$

Cortical reconstruction and volumetric segmentation were carried out with the FreeSurfer image analysis suite version $6.0 .{ }^{23}$ Specifically, automatic parcellation and segmentation protocols were conducted using the recon-all stream to obtain total, cortical, and subcortical brain volumes. All images were inspected for surface reconstruction accuracy using automated and manual method. ${ }^{24}$ Based on previous research investigating brain abnormalities in psychiatric disorders, ${ }^{11-15}$ ten volumetric brain measures were studied as outcomes; including total brain volume (TBV), cortical gray matter (GM), total white matter (WM), subcortical GM, ventricular volume and cerebellum as global segmented brain measurements; and amygdala-hippocampus complex, caudate, putamen and thalamus as subcortical brain volumes. Correlations between the brain measurements are shown in Figure S2, available online. 


\section{Genotyping}

DNA samples were collected from cord blood at birth or from venipuncture during a visit to the research center on Illumina $610 \mathrm{~K}$ and 660K SNP arrays depending on collection time (Illumina, San Diego, CA, USA). Further details on genotype calling procedures in Generation R Study can be found elsewhere. ${ }^{25}$ Information on quality control procedures of the genotype data and principal component analysis can be in in Supplementary Material (see Supplement 1, available online).

\section{Polygenic scoring}

Only participants with European ancestry were selected for the polygenic scoring. Genotype data that passed quality control was used to compute polygenic scores based on GWAS results for five psychiatric traits, including schizophrenia (SCZ), bipolar disorder (BD), major depression (MDD), attention-deficit hyperactivity disorder (ADHD) and autism spectrum disorder (ASD) from the Psychiatric Genomics Consortium. In addition, we calculated polygenic scores for educational attainment (EA) and intelligence. Supplementary Table S1 (available online) provides an overview of the GWAS studies used for PGS calculation. For intelligence, we repeated the GWAS meta-analysis after exclusion of Generation R to ensure independence of discovery and target sample.

Polygenic scores were computed using LDpred. ${ }^{26}$ This polygenic scoring method infers the posterior mean effect size of each marker by using a prior on effect size distribution and LD information from a reference genotype panel. The LDpred algorithm has improved prediction accuracy compared to traditional methods. Six PGS were computed for each trait corresponding to six priors that determined the proportion of SNPs with a causal effect $(0.01,0.05,0.1,0.5,1$ 
and infinitesimal). All polygenic scores were standardized to a mean of 0 and a standard deviation of 1. Correlations between the PGS are shown in Figure S3, available online.

\section{Statistical Analysis}

Multiple linear regression analyses were conducted using R statistical software package, version 3.3.1 (http: www.r-project.org/). To examine whether genetic susceptibility for major psychiatric disorders and cognition is related to brain morphology, each PGS was tested for association with each brain measure individually. In these models, brain measurements were assigned as the dependent variables with PGS for SCZ, BD, ADHD, ASD, EA or intelligence generated at six LDpred priors as independent variables. Models with TBV as outcome were adjusted by sex, age and four genetic principal components. Models for the rest of brain measurements were additionally adjusted by total intracranial volume.

We corrected for multiple testing across all PGS, generated at six different priors, tested for association with ten brain measurements using the false discovery rate (FDR) method. ${ }^{27}$ Results at $P_{F D R}<0.05$ were considered statistically significant.

For statistically significant associations showing a consistent pattern of results, we performed mediation analyses to examine whether differences in the associated brain regions mediated associations between the PGS and the phenotypic manifestation of the PGS trait. Multiple linear regressions analyses were conducted to examine associations between PGS, brain measurements and behavioral phenotypes adjusting for the same covariates included in the primary analyses and age at behavioral assessment. The direct effect (DE), indirect effect (IE), and total effect (TE) were estimated using the "mediation" package in R. As long as the assumptions of the mediation analysis are met, the DE represents the effect of genetic susceptibility on behavioral phenotypes after controlling for variation in brain morphology, and the IE represents the 
estimated effect of polygenic susceptibility operating through brain morphology. ${ }^{28}$ The proportion of mediation by brain morphology can be calculated as the ratio of IE to TE. Given the data available in Generation R, mediation analyses were only feasible for associations with PGS for psychiatric disorders for which behavioral data was assessed when children were between 8-11 years of age (Mean=9.7, $\mathrm{SD}=0.23$, range $=8.85-11.54)$ using the $(\mathrm{CBCL} / 6-18){ }^{29}$ Genetic, neuroimaging and behavioral data were available for 1053 participants. Further details on behavioral assessment can be found elsewhere. ${ }^{21}$ For psychiatric disorders with sex differences in prevalence, we also conducted stratified analysis by sex.

To elucidate whether each cognitive trait independently contributed to variation in the brain measurement, we performed sensitivity analyses for the analyses between the PGS for EA and intelligence with TBV, mutually adjusting using the PGS for intelligence and EA, respectively.

\section{RESULTS}

Sample characteristics

A total of 1,139 children were included in the present study of whom $49.30 \%(n=561)$ were females, and the mean age was 10.16 years $(\mathrm{SD}=0.60$, range $=8.72-11.99)$.

\section{Effects of PGS on brain morphology}

Figure 1 summarizes associations between the PGS for psychiatric disorders and cognition calculated at six priors and brain volumes. Full results for these associations are detailed in Table S2, available online.

No significant associations were observed between PGS for SCZ and BD and brain measurements. 
Higher genetic susceptibility for MDD was consistently related to smaller TBV showing the strongest association for the infinitesimal prior $\left(\beta=-0.07, \mathrm{SE}=0.03 ; P_{\text {uncorrected }}=0.009\right)$. PGS for MDD also showed negative associations with total WM (prior $=0.01$ : $\beta=-0.03, \mathrm{SE}=0.01$, $P_{\text {uncorrected }}=0.043$ ), cerebellum volume (prior $=0.5: \beta=-0.05, \mathrm{SE}=0.02, P_{\text {uncorrected }}=0.042$; prior $=1$ : $\beta=-0.05, \mathrm{SE}=0.02, P_{\text {uncorrected }}=0.040$ ), and thalamus volume (prior $=0.01: \beta=-0.05, \mathrm{SE}=0.02$, $\left.P_{\text {uncorrected }}=0.009\right)$. However, following FDR-correction none of these associations remained significant.

PGS for ADHD were associated with smaller TBV and caudate volume across all priors although associations did not reach statistical significance for prior 0.01 in the case of TBV, and prior 1 in the case of caudate volume. The strongest association with TBV was observed at the infinitesimal prior $\left(\beta=-0.07, \mathrm{SE}=0.03 ; P_{\text {uncorrected }}=0.006\right)$ while the strongest association with caudate volume was observed at prior $0.01\left(\beta=-0.08\right.$, SE=0.03; $\left.P_{\text {uncorrected }}=7.49 \times 10^{-4}\right)$, and remained significant after FDR-correction.

PGS for ASD showed positive associations with TBV at all priors except at prior 0.01 which did not reach significance, but did show the same direction of effect. The largest magnitude of the association was observed at prior $1\left(\beta=0.07, \mathrm{SE}=0.03 ; P_{\text {uncorrected }}=7.75 \times 10^{-3}\right)$. These associations did not surpass FDR-correction.

The EA PGS were consistently associated with larger TBV (strongest prior 0.5 : $\beta=0.14$, $\mathrm{SE}=0.03, P_{\text {uncorrected }}=7.12 \times 10^{-8}$ ) and remained significant after FDR-correction. Associations at prior 0.05 did not reach significance but showed the same direction of effect. Higher genetic susceptibility for EA was also associated with larger volumes of subcortical GM (prior=0.05: $\beta=0.04, \mathrm{SE}=0.02, P_{\text {uncorrected }}=0.046$ ), cerebellum (prior $=0.1: \beta=0.05, \mathrm{SE}=0.02, P_{\text {uncorrected }}=0.047$ ), 
putamen (prior $=0.05: \beta=0.06, \mathrm{SE}=0.03, P_{\text {uncorrected }}=0.016$ ) and thalamus at multiples priors (strongest prior $=1: \beta=0.05, \mathrm{SE}=0.02, P_{\text {uncorrected }}=0.012$ ).

Higher genetic susceptibility for intelligence was significantly related to larger TBV for most of the priors, used even after FDR-correction (strongest prior 0.5: $\beta=0.12, \mathrm{SE}=0.03 ; P_{\text {uncorrected }}=$ $\left.6.87 \times 10^{-7}\right)$. Other associations not surviving FDR-correction included a positive association with subcortical GM (Infinitesimal prior: $\beta=0.04, \mathrm{SE}=0.02, P_{\text {uncorrected }}=0.024$ ) and positive associations with cerebellum volume (priors 0.01 and $0.05: \beta=0.07, \mathrm{SE}=0.02, P_{\text {uncorrected }}=0.003$ ).

\section{Mediation analysis}

Only the association between polygenic risk for ADHD and caudate volume survived FDRcorrection, therefore, we tested whether caudate volume mediated the association between polygenic risk for ADHD and the attention problems CBCL syndrome scale. The caudate nucleus met the conditions to act as a mediator, since it showed a negative significant association with attention problems $(\beta=-0.06, \mathrm{SE}=0.00, P=0.029)$. Similarly, polygenic risk for ADHD was significantly associated with attention problems $(\beta=0.12, \mathrm{SE}=0.00, P=5.36 \times 10-5)$. However, mediation was $4.6 \%$ and not significant within the entire sample (Figure 2). In analyses stratified by sex, mediation was significant only in boys indicating that $11 \%$ of the association between polygenic risk for ADHD (prior=0.01) and attention problems may be mediated by differences in caudate volume (Figure 2).

\section{Sensitivity analysis}

Analyses mutually adjusting for polygenic susceptibility for EA and intelligence at prior 0.05 showed that the PGS for both traits were independently associated with TBV (PGS for EA: $\beta=0.10, \mathrm{SE}=0.03 ; P=2.6 \times 10^{-4} ; \mathrm{PGS}$ for intelligence $\left.=\beta=0.08, \mathrm{SE}=0.03 ; P=0.003\right)$. 


\section{DISCUSSION}

We examined whether polygenic susceptibility for psychiatric disorders and cognition was associated with brain morphology in children. We found a consistent pattern of results across priors indicating that the polygenic risk for ADHD was negatively associated with caudate volume, with the finding with at prior of 0.01 surviving multiple testing correction. Polygenic susceptibility for intelligence and EA showed a positive relationship with TBV that was consistent across all priors used, although generally not significant for the more stringent priors (i.e. 0.05 and 0.01). Polygenic risk for SCZ and BD did not show significant associations with brain morphology, however, several brain measurements were related to PGS for MDD and ASD, although none of these associations survived multiple testing correction. These findings indicate the neurobiological manifestation of polygenic susceptibility for ADHD, intelligence, and EA involves early morphological differences in caudate and total brain volume during development.

Whole-brain and caudate volume reductions have been related to ADHD in a recent megaanalysis. ${ }^{14}$ Given the high heritability of $\mathrm{ADHD},{ }^{30}$ we expected that regions previously associated with the disorder would also be associated with polygenic risk for ADHD. To the best of our knowledge, this is the first study providing evidence indicating that polygenic risk for ADHD may be, at least partially, underlying TBV and caudate reductions in childhood. These findings are particularly relevant in the case of the caudate volume reduction, one of the most replicated findings in ADHD. ${ }^{31}$ Interestingly, our results suggest that reduced caudate volume may be mediating the association between polygenic risk for ADHD and attention problems in boys. ADHD is 2 to 9 times more prevalent in boys during childhood and adolescence. ${ }^{32}$ Gender differences in brain morphology have been used to investigate whether ADHD-related brain 
abnormalities are more pronounced in males compared to females. Although caudate volume did not show sex effects in the mega-analysis conducted by Hoogman et $a l,{ }^{14}$ another study examining volume and shape of the basal ganglia observed smaller caudate volumes in boys with ADHD compared to male controls and no differences among girls. ${ }^{33}$ Similarly, smaller caudate volumes have been found in adult male ADHD patients compared to male controls, while no differences were observed among females. ${ }^{34}$ Our findings are in line with these studies supporting that different genetically-influenced neurobiological mechanisms may be operating in males and females in the context of ADHD.

The EA polygenic scores were associated with larger TBV. Intracranial volume has been previously related to EA genetic variants by applying LD Score regression methodology. ${ }^{35}$ Genetic variants for EA or other traits, may affect TBV directly, through direct gene expression, via gene-environment interaction or correlation mechanisms, or through intermediate phenotypes. Remarkably, an important number of SNPs related to EA are located within genomic regions regulating gene expression in the fetal brain and genes mainly expressed in neural tissue. ${ }^{35}$ These genes are especially active during the prenatal period and enriched for biological pathways involved in neural development. ${ }^{35}$ Thus, it is likely that polygenic susceptibility for EA includes variants that directly promote optimal brain development. Another possibility would be that EA genetic variants could influence brain morphology through environmental exposures that positively affect brain development, which would imply geneenvironment correlation effects. In fact, children with higher genetic loading for EA tend to be raised in socioeconomically advantaged environments, ${ }^{36}$ which positively impacts brain development. ${ }^{37}$ Finally, it is also important to note that genetic associations with EA may be mediated by other phenotypes such as intelligence or personality traits which are considered 
intermediate phenotypes for EA. ${ }^{38}$ In addition, higher genetic loading for EA was nominally associated with larger thalamus volumes at multiple priors. The thalamus is a major hub in the brain, relaying multimodal information covering a wide range of cognitive functions, including learning, memory, inhibitory control, decision-making, control of visual orienting responses and attention. ${ }^{39}$ Thus, a relationship between polygenic susceptibility for cognitive functions relevant for education attainment with increased volume of the thalamus is neurobiologically plausible. Not surprisingly, our findings on polygenic susceptibility for intelligence and EA largely overlap in terms of strength of the association and variance explained of TBV. Similarly to EA, genetic variants related to intelligence were identified in genes predominantly expressed in brain tissue. ${ }^{40}$ Interestingly, polygenic susceptibility for both EA and intelligence influenced TBV independently of each other. Since the correlation between the PRS for EA and intelligence were not extremely strong (Figure S3, available online), we speculate that genetic variants related to these traits may act through different pathways. Studies have shown that TBV is positively correlated with intelligence, accounting for about $16 \%$ of the variance in IQ. ${ }^{41}$ Furthermore, our results indicate a shared genetic overlap between IQ and brain size, which is in line with twin studies suggesting that the association between these phenotypes is mainly of genetic origin. ${ }^{42}$ Contrary to our hypothesis, polygenic risk for SCZ was not associated with brain morphological variation between the ages of 9-to-11 years. This is in line with previous research in adults. ${ }^{17,19}$ However, this null finding was surprising, as we found an association between the PGS for SCZ and internalizing symptoms, and especially thought problems. ${ }^{4}$ Behavioral effects of polygenic risk for SCZ must have neural correlates that we were unable to detect for several potential reasons. First, it is possible that the neural correlates of SCZ PGS are related to other neurobiological phenotypes not quantified in our study. This would not be the case for white 
matter measurements including global and tract-specific fractional anisotropy and mean diffusivity that were tested for association with polygenic risk for SCZ in this sample, revealing negative results. ${ }^{43}$ Also, polygenic risk for SCZ has been associated with functional brain parameters, such as brain activation patterns detectable with fMRI during cognitive tasks in adolescents. ${ }^{44,45}$ Second, brain structural abnormalities related to genetic risk for schizophrenia may only be detectable in young individuals beginning in the prodromal phase, when the illness has begun to show clinical manifestations. These finding become 'unmasked' as the illness progresses, making it very difficult to observe in general population samples, especially early in life. Finally, genetic risk for SCZ has been related to nonparticipation in a large longitudinal population-based cohort studies, ${ }^{46}$ implying that individuals at high genetic risk may be underrepresented. This would lead to underestimating effects of these genetic variants on neurodevelopmental outcomes. However, PGS for SCZ were very similar within the Generation R participants with EU ancestry comparing those included versus excluded in the current study (Table S3, available online).

Other interesting findings, albeit not surpassing multiple testing correction, include positive relationships between PGS for ASD and TBV, and negative associations between MDD PGS and TBV. Converging evidence points to an increased brain size as a characteristic brain abnormality of young children with ASD. ${ }^{47}$ Our results suggest that this association may be accounted by common genetic variants increasing the risk for ASD. Although it may seem counterintuitive that polygenic risk for ASD shows the same direction of effects on TBV as PGS for EA and intelligence, it has been shown that polygenic risk for these traits is highly correlated and that genetic risk for ASD may act through different etiological pathways. ${ }^{48}$ Regarding MDD PGS, widespread GM and subcortical volume reductions have been reported in individuals affected by 
MDD. ${ }^{49}$ Comparatively, less research has been conducted on global structural brain measures such as TVB. Overall, further research is needed to confirm these potential associations.

Our results should be interpreted in the context of several strengths and limitations. The strengths of the current study include the large sample size and homogeneity with respect to recruitment, exclusion criteria, scanner, image acquisition and pre-processing methods, which is especially valuable in the imaging genetics field. That said, the current sample is adequate for detecting significant effect sizes above 0.08 at $80 \%$ power, thus, reported smaller effect sizes, which correspond to negative findings, should be interpreted with caution. The main limitation of the study is the cross-sectional design. Studies including brain morphological measurements at multiple time points are needed to examine whether polygenic risk for psychiatric disorders and cognition contribute to changes in developmental trajectories. Another limitation is that the polygenic scores typically explain only a small proportion of the total phenotypic variance of complex traits. ${ }^{1,2}$ It is also important to notice that predictive accuracy of PGS is related to sample size in the discovery sample, which substantially varies among the different traits for PGS examined in the current study. ${ }^{50}$ This should be considered when comparing results for the different traits examined. Nevertheless, we used summary statistics from the most recent, and thus more powerful GWAS conducted on psychiatric disorders to date, which represents an advantage over previous studies using PGS based on GWAS conducted on smaller samples.

To conclude, we found a relationship between polygenic susceptibility for intelligence and EA and TBV in school-age children. We also found effects of ADHD polygenic risk for caudate volume. Interestingly, we found evidence for mediation only in boys, where differences in the caudate volume accounted for $11 \%$ of the association between polygenic risk for ADHD and attention problems at 9 years-of-age. Overall, our findings provide molecular genetic evidence 
for the relationship between polygenic susceptibility for cognition and ADHD with early differences in brain morphology. 


\section{References}

1. Visscher PM, Wray NR, Zhang Q, et al. 10 Years of GWAS Discovery: Biology, Function, and Translation. Am J Hum Genet. 2017;101(1):5-22.

2. Wray NR, Lee SH, Mehta D, Vinkhuyzen AAE, Dudbridge F, Middeldorp CM. Research Review: Polygenic methods and their application to psychiatric traits. J Child Psychol Psychiatry Allied Discip. 2014;55(10):1068-1087.

3. Riglin L, Collishaw S, Richards A, et al. Schizophrenia risk alleles and neurodevelopmental outcomes in childhood: a population-based cohort study. Lancet Psychiatry. 2017;4(1):57-62.

4. Jansen PR, Polderman TJC, Bolhuis K, et al. Polygenic scores for schizophrenia and educational attainment are associated with behavioural problems in early childhood in the general population. J Child Psychol Psychiatry. 2018;59(1):39-47.

5. Nivard MG, Gage SH, Hottenga JJ, et al. Genetic Overlap Between Schizophrenia and Developmental Psychopathology: Longitudinal and Multivariate Polygenic Risk Prediction of Common Psychiatric Traits During Development. Schizophr Bull. 2017;43(6):1197-1207.

6. Riglin L, Collishaw S, Richards A, et al. The impact of schizophrenia and mood disorder risk alleles on emotional problems: investigating change from childhood to middle age. Psychol Med. December 2017:1-6.

7. Mistry S, Harrison JR, Smith DJ, Escott-Price V, Zammit S. The use of polygenic risk scores to identify phenotypes associated with genetic risk of bipolar disorder and depression: A systematic review. J Affect Disord. 2018;234:148-155.

8. Martin J, Hamshere ML, Stergiakouli E, O’Donovan MC, Thapar A. Genetic risk for 
attention-deficit/hyperactivity disorder contributes to neurodevelopmental traits in the general population. Biol Psychiatry. 2014;76(8):664-671.

9. Stergiakouli E, Martin J, Hamshere ML, et al. Association between polygenic risk scores for attention-deficit hyperactivity disorder and educational and cognitive outcomes in the general population. Int J Epidemiol. 2017;46(2):421-428.

10. Jansen AG, Mous SE, White T, Posthuma D, Polderman TJC. What Twin Studies Tell Us About the Heritability of Brain Development, Morphology, and Function: A Review. Neuropsychol Rev. 2015;25(1):27-46.

11. van Erp TGM, Walton E, Hibar DP, et al. Cortical Brain Abnormalities in 4474 Individuals With Schizophrenia and 5098 Control Subjects via the Enhancing Neuro Imaging Genetics Through Meta Analysis (ENIGMA) Consortium. Biol Psychiatry. May 2018 (In press).

12. Hibar DP, Westlye LT, van Erp TGM, et al. Subcortical volumetric abnormalities in bipolar disorder. Mol Psychiatry. 2016;21(12):1710-1716.

13. Schmaal L, Veltman DJ, van Erp TGM, et al. Subcortical brain alterations in major depressive disorder: findings from the ENIGMA Major Depressive Disorder working group. Mol Psychiatry. 2015;21:1-7.

14. Hoogman M, Bralten J, Hibar DP, et al. Subcortical brain volume differences in participants with attention deficit hyperactivity disorder in children and adults: a crosssectional mega-analysis. The Lancet Psychiatry. 2017;4(4):310-319.

15. van Rooij D, Anagnostou E, Arango C, et al. Cortical and Subcortical Brain Morphometry Differences Between Patients With Autism Spectrum Disorder and Healthy Individuals Across the Lifespan: Results From the ENIGMA ASD Working Group. Am J Psychiatry. 
2018;175(4):359-369.

16. Terwisscha van Scheltinga AF, Bakker SC, van Haren NE, et al. Genetic schizophrenia risk variants jointly modulate total brain and white matter volume. Biol Psychiatry. 2013;73(6):525-531.

17. Van Der Auwera S, Wittfeld K, Homuth G, Teumer A, Hegenscheid K, Grabe HJ. No Association between Polygenic Risk for Schizophrenia and Brain Volume in the General Population. Biol Psychiatry. 2015;78(11):e41-e42.

18. Caseras X, Tansey KE, Foley S, Linden D. Association between genetic risk scoring for schizophrenia and bipolar disorder with regional subcortical volumes. Transl Psychiatry. 2015;5:e692.

19. Reus LM, Shen X, Gibson J, et al. Association of polygenic risk for major psychiatric illness with subcortical volumes and white matter integrity in UK Biobank. Sci Rep. 2017;7:42140.

20. Tiemeier H, Velders FP, Szekely E, et al. The Generation R Study: A Review of Design, Findings to Date, and a Study of the 5-HTTLPR by Environmental Interaction From Fetal Life Onward. J Am Acad Child Adolesc Psychiatry. 2012;51(11):1119-1135.e7.

21. White T, Muetzel RL, El Marroun H, et al. Paediatric population neuroimaging and the Generation R Study: the second wave. Eur J Epidemiol. 2017;33:99-125.

22. Jansen PR, Dremmen M, van den Berg A, et al. Incidental Findings on Brain Imaging in the General Pediatric Population. N Engl J Med. 2017;377(16):1593-1595.

23. Fischl B. FreeSurfer. Neuroimage. 2012;62(2):774-781.

24. White T, Jansen PR, Muetzel RL, et al. Automated quality assessment of structural magnetic resonance images in children: Comparison with visual inspection and surface- 
based reconstruction. Hum Brain Mapp. 2018;39(3):1218-1231.

25. Medina-Gomez C, Felix JF, Estrada K, et al. Challenges in conducting genome-wide association studies in highly admixed multi-ethnic populations: the Generation R Study. Eur J Epidemiol. 2015;30(4):317-330.

26. Vilhjálmsson BJ, Yang J, Finucane HK, et al. Modeling Linkage Disequilibrium Increases Accuracy of Polygenic Risk Scores. Am J Hum Genet. 2015;97(4):576-592.

27. Benjamini Y, Hochberg Y. Controlling the false discovery rate: a practical and powerful approach to multiple testing. J R Stat Soc. 1995;57(1):289-300.

28. Valeri L, VanderWeele TJ. Mediation analysis allowing for exposure-mediator interactions and causal interpretation: Theoretical assumptions and implementation with SAS and SPSS macros. Psychol Methods. 2013;18(2):137-150.

29. Achenbach, T.M., \& Rescorla, L.A. Manual for the ASEBA Preschool Forms \& Profiles. Burlington: University of Vermont, Research Center for Children, Youth, \& Families; 2000.

30. Thapar A, Cooper M, Eyre O, Langley K. What have we learnt about the causes of ADHD? J Child Psychol Psychiatry. 2013;54(1):3-16.

31. Nakao T, Radua J, Rubia K, Mataix-Cols D. Gray Matter Volume Abnormalities in ADHD: Voxel-Based Meta-Analysis Exploring the Effects of Age and Stimulant Medication. Am J Psychiatry. 2011;168(11):1154-1163.

32. Polanczyk G, de Lima MS, Horta BL, Biederman J, Rohde LA. The Worldwide Prevalence of ADHD: A Systematic Review and Metaregression Analysis. Am J Psychiatry. 2007;164(6):942-948.

33. Qiu A, Crocetti D, Adler M, et al. Basal Ganglia Volume and Shape in Children With 
Attention Deficit Hyperactivity Disorder. Am J Psychiatry. 2009;166(1):74-82.

34. Onnink AMH, Zwiers MP, Hoogman M, et al. Brain alterations in adult ADHD: Effects of gender, treatment and comorbid depression. Eur Neuropsychopharmacol. 2014;24(3):397409.

35. Okbay A, Beauchamp JP, Fontana MA, et al. Genome-wide association study identifies 74 loci associated with educational attainment. Nature. 2016;533(7604):539-542.

36. Belsky DW, Moffitt TE, Corcoran DL, et al. The Genetics of Success: How SingleNucleotide Polymorphisms Associated With Educational Attainment Relate to LifeCourse Development. Psychol Sci. 2016;27(7):957-972.

37. Noble KG, Houston SM, Brito NH, et al. Family income, parental education and brain structure in children and adolescents. Nat Neurosci. 2015;18(5):773-778.

38. Krapohl E, Rimfeld K, Shakeshaft NG, et al. The high heritability of educational achievement reflects many genetically influenced traits, not just intelligence. Proc Natl Acad Sci. 2014;111(42):15273-15278.

39. Mitchell AS, Sherman SM, Sommer MA, Mair RG, Vertes RP, Chudasama Y. Advances in Understanding Mechanisms of Thalamic Relays in Cognition and Behavior. J Neurosci. 2014;34(46):15340-15346.

40. Savage JE, Jansen PR, Stringer S, et al. GWAS meta-analysis in 269,867 individuals identifies new genetic and functional links to intelligence. bioRxiv. September 2017:184853.

41. Haier RJ, Jung RE, Yeo RA, Head K, Alkire MT. Structural brain variation and general intelligence. Neuroimage. 2004;23(1):425-433.

42. Posthuma D, De Geus EJC, Baaré WFC, Hulshoff Pol HE, Kahn RS, Boomsma DI. The 
association between brain volume and intelligence is of genetic origin. Nat Neurosci. 2002;5(2):83-84.

43. Jansen PR, Muetzel RL, Polderman TJ, et al. Polygenic Scores for Neuropscyhiatric Traits and White Matter Microstructure in the Pediatric Population. Biol psychiatry Cogn Neurosci neuroimaging. (Accepted).

44. Lancaster TM, Ihssen N, Brindley LM, et al. Associations between polygenic risk for schizophrenia and brain function during probabilistic learning in healthy individuals. Hum Brain Mapp. 2016;37(2):491-500.

45. Whalley HC, Hall L, Romaniuk L, et al. Impact of cross-disorder polygenic risk on frontal brain activation with specific effect of schizophrenia risk. Schizophr Res. 2015;161(23):484-489.

46. Martin J, Tilling K, Hubbard L, et al. Association of genetic risk for schizophrenia with nonparticipation over time in a population-based cohort study. Am J Epidemiol. 2016.

47. Riddle K, Cascio CJ, Woodward ND. Brain structure in autism: a voxel-based morphometry analysis of the Autism Brain Imaging Database Exchange (ABIDE). Brain Imaging Behav. 2017;11(2):541-551.

48. Weiner DJ, Wigdor EM, Ripke S, et al. Polygenic transmission disequilibrium confirms that common and rare variation act additively to create risk for autism spectrum disorders. Nat Genet. 2017;49(7):978-985.

49. Grieve SM, Korgaonkar MS, Koslow SH, Gordon E, Williams LM. Widespread reductions in gray matter volume in depression. NeuroImage Clin. 2013;3:332-339.

50. Dudbridge F. Power and Predictive Accuracy of Polygenic Risk Scores. Wray NR, ed. PLoS Genet. 2013;9(3):e1003348. 


\section{Figure Legends}

Figure 1. Associations between polygenic scores for schizophrenia (SCZ), bipolar disorder (BD), major depression disorder (MDD), attention-deficit hyperactivity disorder (ADHD), autism spectrum disorder (ASD), educational attainment (EA) and intelligence computed at six priors $(0.01,0.05,0.1,0.5,1$ and infinitesimal) and brain volumes adjusted for sex, age, total intracranial volume (except associations with TBV) and the first four genetic components (n=1139). $P$-uncorrected values $<0.05$ are indicated with asterisk $\left(^{*}\right), P$-FDR $<0.05$ are indicated with a cross $(\mathrm{X})$.

Figure 2. Mediation analysis of the estimated effect (95\% CIs) of polygenic risk for ADHD (prior=0.01) on attention problems (CBCL syndrome scale reported by mothers) through caudate volume in the entire sample $(n=1053)$ and stratified by sex (boys, $n=535$; girls, $n=518)$. The figure shows caudate volume as a potential mediator, the estimates of indirect and direct effect, and the proportion of mediation. All models were adjusted for age at MRI scan, age at CBCL administration, total intracranial volume and the first four genetic components. 


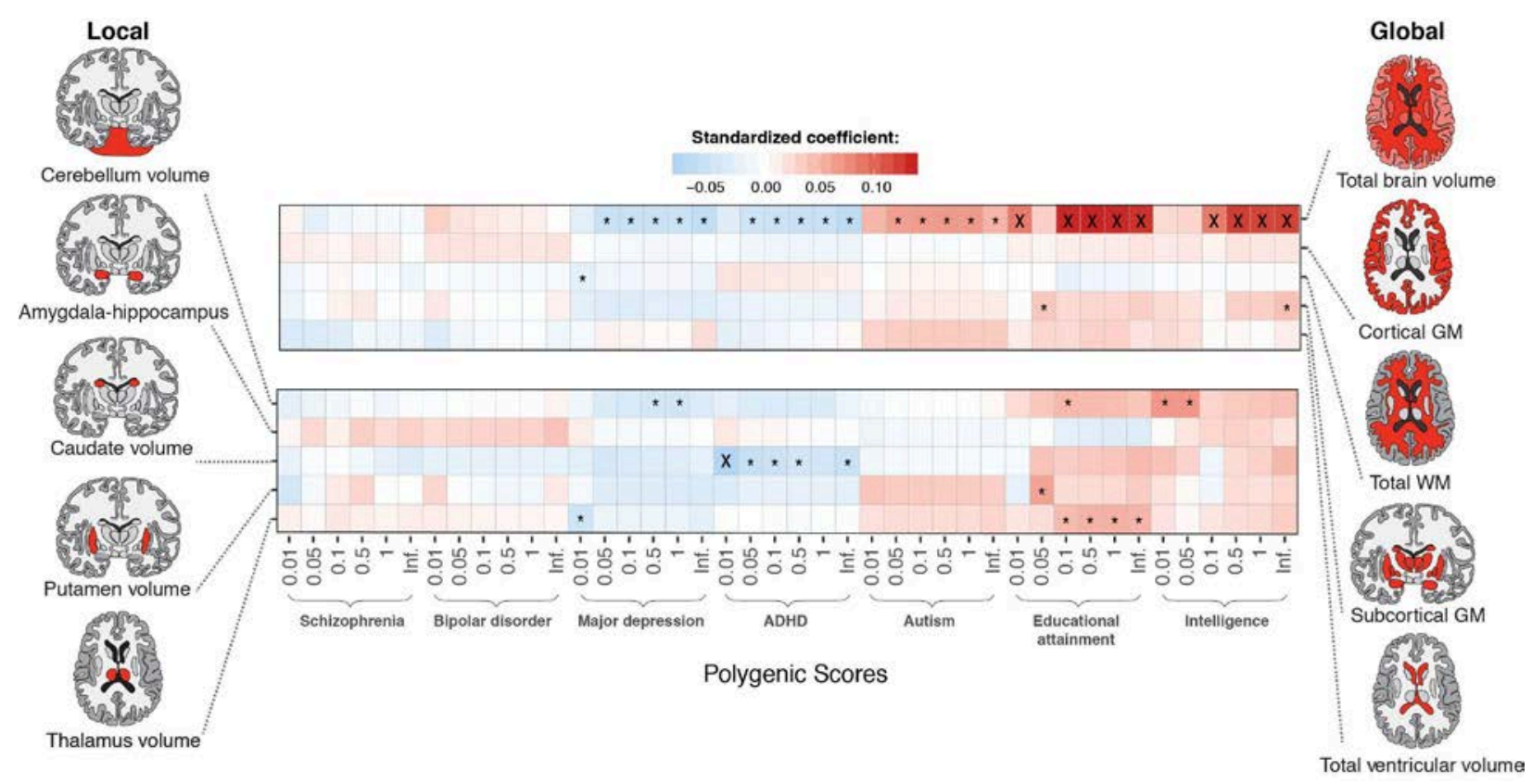

Figure 1. Associations between polygenic scores for schizophrenia (SCZ), bipolar disorder (BD), major depression disorder (MDD), attention-deficit hyperactivity disorder (ADHD), autism spectrum disorder (ASD), educational attainment (EA) and intelligence computed at six priors $(0.01,0.05,0.1,0.5,1$ and infinitesimal) and brain volumes adjusted for sex, age, total intracranial volume (except associations with TBV) and the first four genetic components (n=1139). $P$-uncorrected values $<0.05$ are indicated with asterisk $(*), P$-FDR $<0.05$ are indicated with a cross $(\mathrm{X})$. 


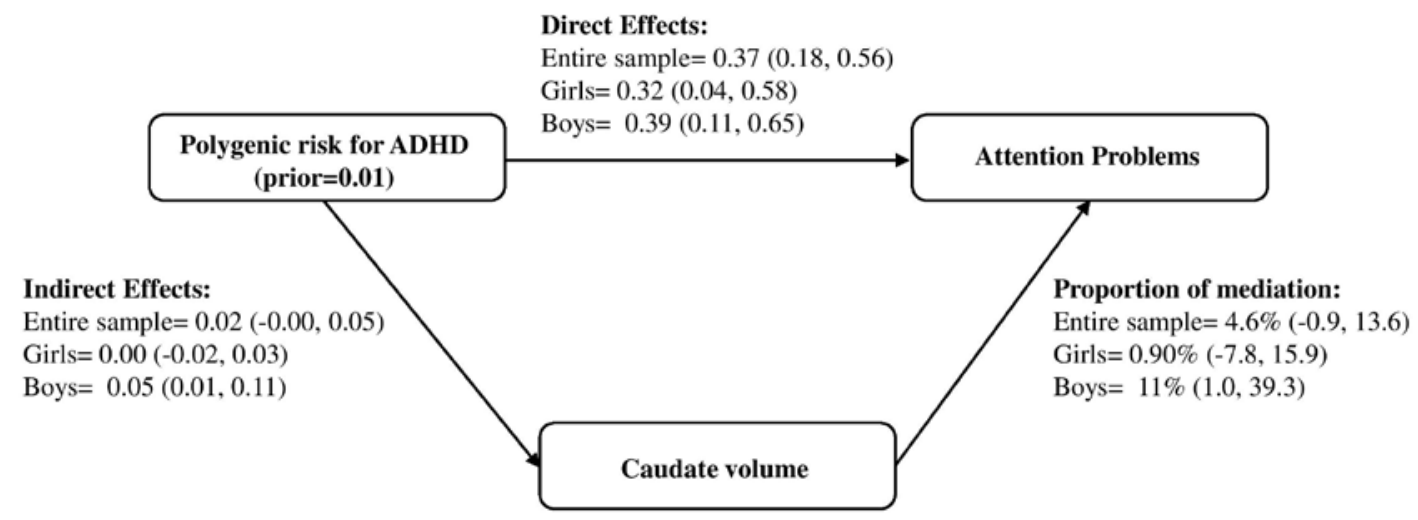

Figure 2. Mediation analysis of the estimated effect (95\% CIs) of polygenic risk for ADHD (prior $=0.01$ ) on attention problems (CBCL syndrome scale reported by mothers) through caudate volume in the entire sample ( $n=1053$ ) and stratified by sex (boys, $n=535$; girls, $n=518$ ). The figure shows caudate volume as a potential mediator, the estimates of indirect and direct effect, and the proportion of mediation. All models were adjusted for age at MRI scan, age at CBCL administration, total intracranial volume and the first four genetic components. 


\section{SUPPLEMENTARY MATERIAL}

Title: Common polygenic variation for psychiatric disorders and cognitive traits and structural brain imaging in the general pediatric population

Short title: Polygenic scores and brain structure in children

Authors: Silvia Alemany. Philip R. Jansen. Ryan L. Muetzel. Natalia Marqués. Hanan El

Marroun. Vincent W.V. Jaddoe. Tinca J.C. Polderman. Henning Tiemeier. Danielle Posthuma. Tonya White.

Supplement 1. Genotyping and imputation.

Figure S1. Flow chart of the study population.

Figure S2. Correlations among the brain MRI measurements of the study (N=1139).

Figure S3. Correlations among the polygenic scores for schizophrenia (SCZ), bipolar disorder (BD), major depression disorder (MDD), attention-deficit/hyperactivity disorder (ADHD), autism spectrum disorders (ASD), educational attainment (EA) and intelligence computed at six priors $(0.01,0.05,0.1,0.5,1$ and infinitesimal) $(\mathrm{N}=1139)$.

Table S1. Summary statistics used to calculate polygenic scores were obtained from the following GWAS. Number of SNPs (N SNPs) included in the PGRS for each trait is indicated.

Table S2. Association results between polygenic scores for schizophrenia (SCZ), bipolar disorder (BD), major depression disorder (MDD), attention-deficit/hyperactivity disorder (ADHD), autism spectrum disorders (ASD), educational attainment (EA) and intelligence computed at six priors (0.01, 0.05, 0.1, 0.5, 1 and infinitesimal) and brain measurements including: total brain volume (TBV), cortical gray matter (GM), total white matter (WM), subcortical GM, total ventricular volume, cerebellum volume, amygdala-hippocampus complex, caudate volume, putamen volume and thalamus volume. Models with TBV as outcome were adjusted by sex, age and four genetic principal components. Models for the rest of brain measurements were additionally adjusted by total intracranial volume.

Table S3. Mean and SD for polygenic scores for schizophrenia in the entire sample of participants with EU ancestry $(\mathrm{N}=2830)$, included $(\mathrm{n}=1139)$ and excluded $(\mathrm{n}=1691)$ in the current study. P-value derived from t-test.

\section{References}




\section{Supplement 1. Genotyping}

DNA samples were collected from cord blood at birth or from venipuncture during a visit to the research center on Illumina $610 \mathrm{~K}$ and $660 \mathrm{~K}$ SNP arrays depending on collection time (Illumina, San Diego, CA, USA). Further details on genotype calling procedures in Generation R Study can be found elsewhere (Medina-Gomez et al. 2015). Quality control at the genotype and individual data level was conducted using PLINK (v1.9) (Purcell et al. 2007). Genotype data quality control included filtering variants for minor allele frequency (MAF $<1 \%$ ), Hardy-Weinberg disequilibrium (HWE, $P<1 \times 10^{-5}$ ) and missing rate $(>5 \%)$. Individuals were filtered on relatedness (pairwise identity-by-descent (IBD) >0.185), genetic and phenotypic sex mismatch, and genotype quality ( $<5 \%$ missing). Polygenic scoring was performed on genotyped SNPs only. 


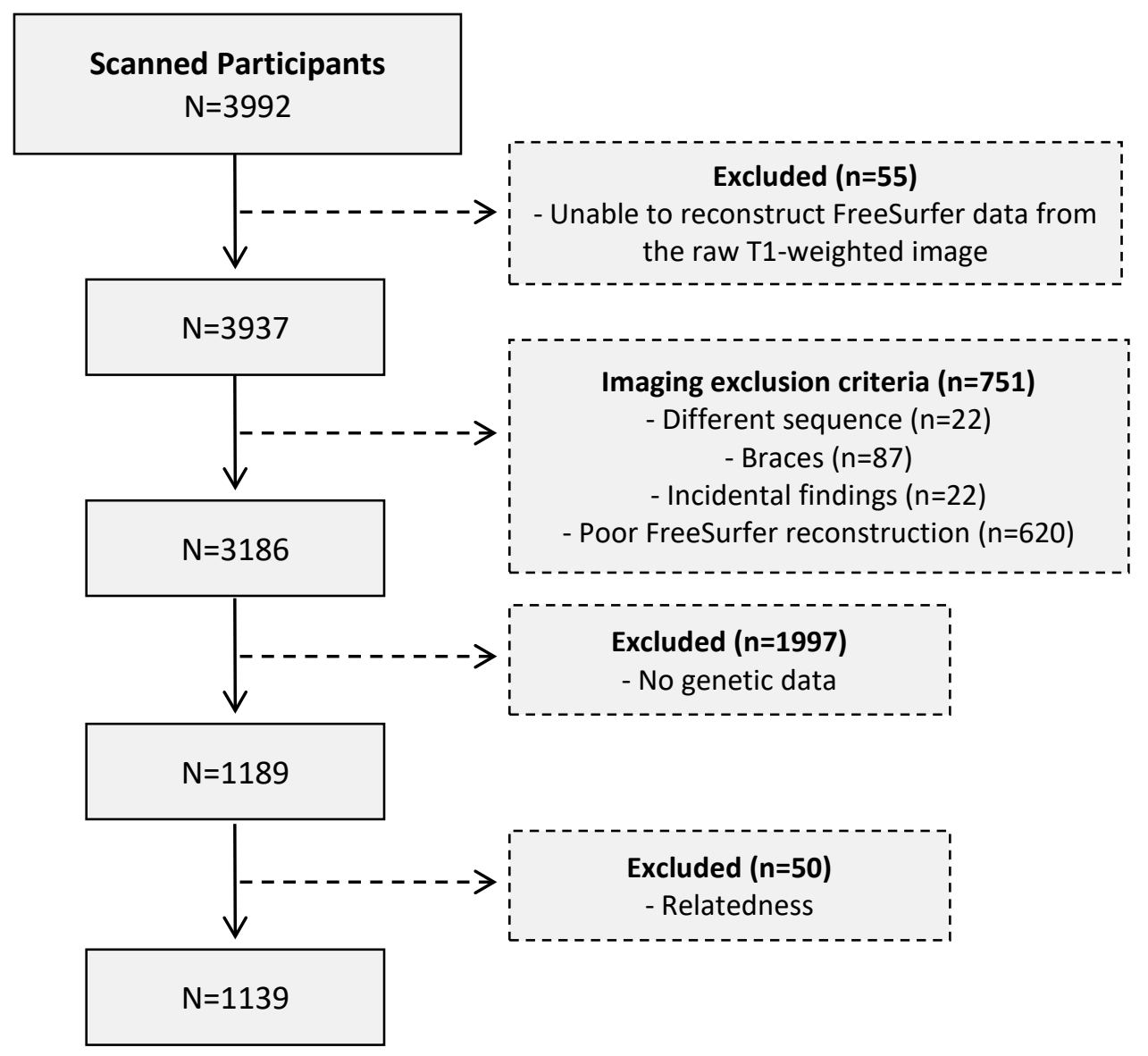

Figure S1. Flow chart of the study population. 


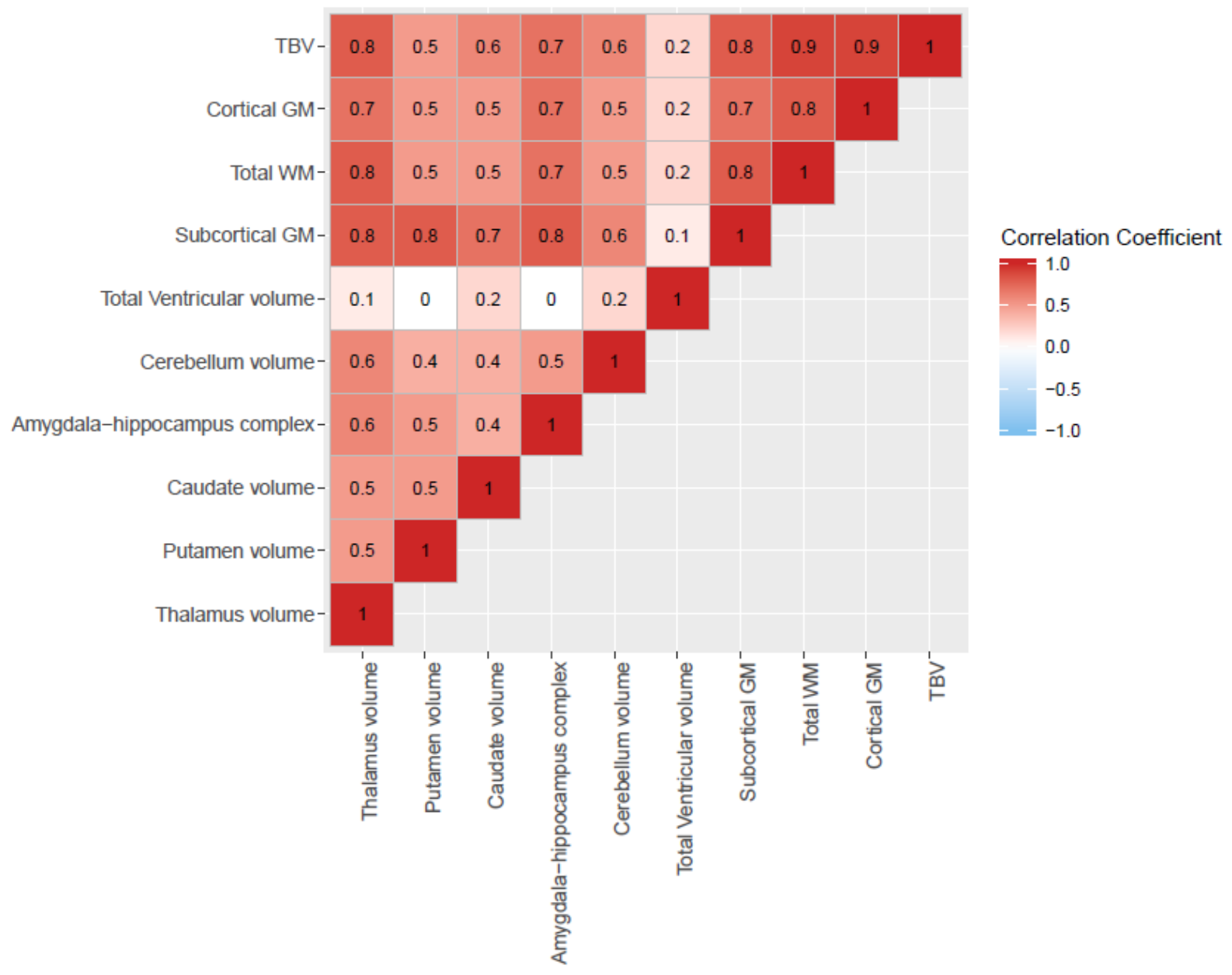

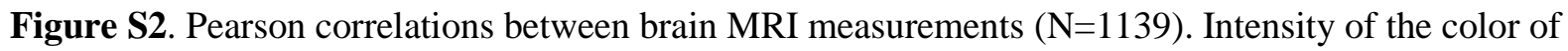
shaded boxes indicates the magnitude of the correlation. Colored boxes indicate significant correlations at $\mathrm{P}<0.05$. 


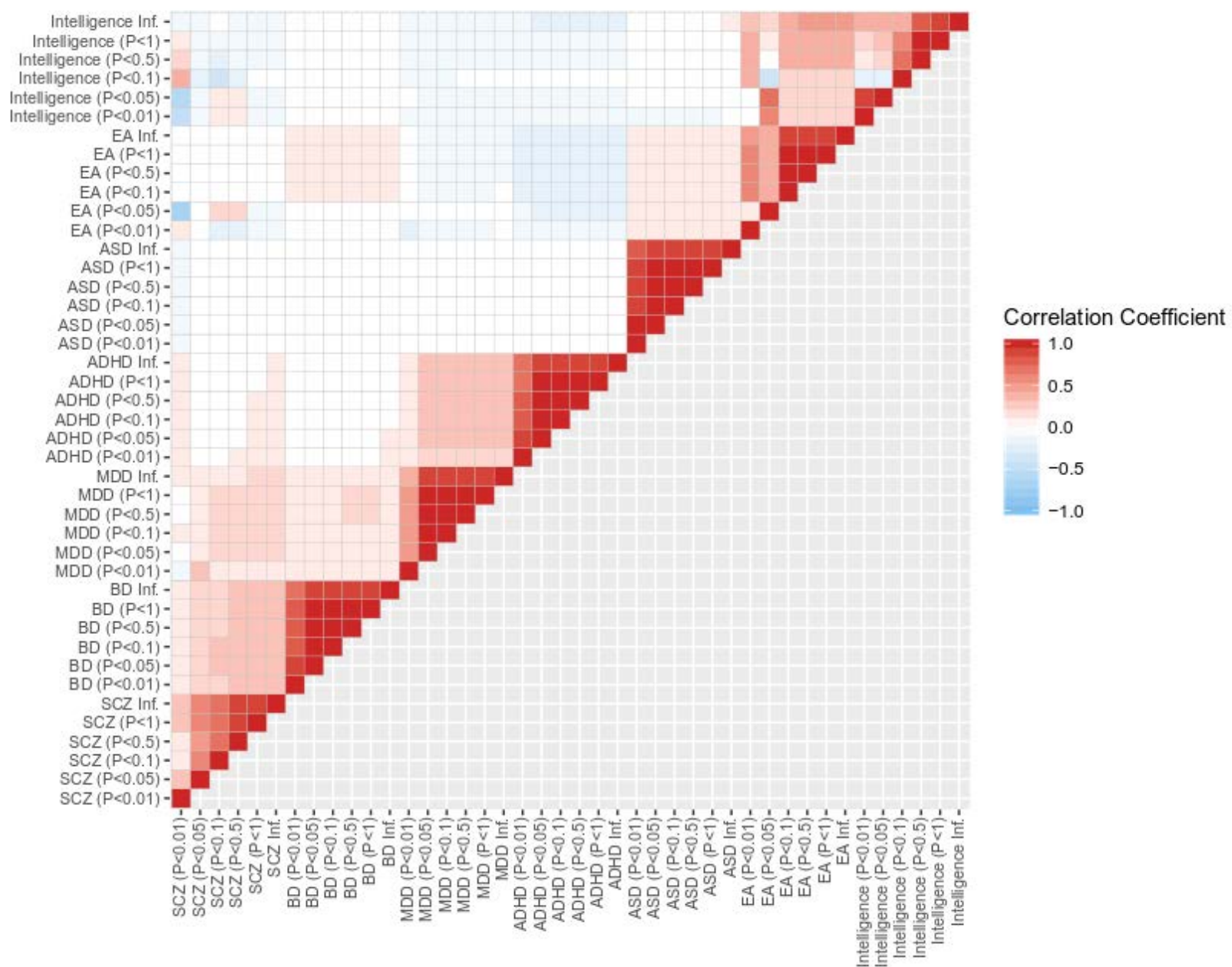

Figure S2. Pearson correlations between the polygenic scores for schizophrenia (SCZ), bipolar disorder (BD), major depression disorder (MDD), attention-deficit/hyperactivity disorder (ADHD), autism spectrum disorders (ASD), educational attainment (EA) and intelligence computed at six priors (0.01, $0.05,0.1,0.5,1$ and infinitesimal) $(\mathrm{N}=1139)$. Intensity of the color of shaded boxes indicates the magnitude of the correlation. Colored boxes indicate significant correlations at $\mathrm{P}<0.05$. 
Table S1. Summary statistics used to calculate polygenic scores were obtained from the following GWAS. Number of SNPs (N SNPs) included in the PGRS for each trait is indicated.

\begin{tabular}{llccc}
\hline Consortium/Cohorts & Trait & N & N SNPs & $\begin{array}{c}\text { Reference } \\
\text { (Ripke et al. 2014) }\end{array}$ \\
PGC & Schizophrenia & 77.096 & 481,162 & (PGC Bipolar Disorder Working Group 2011) \\
PGC & Bipolar Disorder & 16.731 & 473,445 & (Wray et al. 2018) \\
PGC & MDD & 307.354 & 480,813 & (Demontis et al. 2017) \\
PGC & ADHD & 55.374 & 450,347 & (D) \\
SSGAC & ASD & 15.954 & 480,374 & (PGC Autism Spectrum Disorders Working Group 2017) \\
CTG & Educational Attainment & 293,723 & 479,695 & (Savage et al. 2016) \\
\hline Note: PGC, Psychiatric & (Senomics Consortium; SSGAC, Social Science Genetic Association Consortium; CTG, Complex Trait Genetics.
\end{tabular}


Table S2. Association results between polygenic scores for schizophrenia (SCZ), bipolar disorder (BD), major depression disorder (MDD), attentiondeficit/hyperactivity disorder (ADHD), autism spectrum disorders (ASD), educational attainment (EA) and intelligence computed at six priors (0.01, 0.05, 0.1, 0.5, 1 and infinitesimal) and brain measurements including: total brain volume (TBV), cortical gray matter (GM), total white matter (WM), subcortical GM, total ventricular volume, cerebellum volume, amygdala-hippocampus complex, caudate volume, putamen volume and thalamus volume. Models with TBV as outcome were adjusted by sex, age and four genetic principal components. Models for the rest of brain measurements were additionally adjusted by total intracranial volume. Significant results are indicated with an asterisk.

\begin{tabular}{|c|c|c|c|c|c|c|}
\hline PGS & Brain measurement & $\boldsymbol{\beta}$ & SE & P-uncorr. & P-FDR & $\Delta \mathbf{R}^{2}$ \\
\hline \multirow{10}{*}{ SCZ (prior= 0.01) } & TBV & 0.006 & 0.025 & $7.96 \mathrm{E}-01$ & $9.47 \mathrm{E}-01$ & -0.001 \\
\hline & Cortical GM & 0.011 & 0.015 & 4.47E-01 & 7.78E-01 & 0.000 \\
\hline & Total WM & -0.015 & 0.014 & 2.91E-01 & 6.73E-01 & 0.000 \\
\hline & Subcortical GM & -0.019 & 0.018 & 2.97E-01 & 6.73E-01 & 0.000 \\
\hline & Total Ventricular volume & -0.040 & 0.027 & $1.45 \mathrm{E}-01$ & 6.73E-01 & 0.001 \\
\hline & Cerebellum volume & -0.028 & 0.023 & $2.16 \mathrm{E}-01$ & 6.73E-01 & 0.000 \\
\hline & Amygdala-hippocampus complex & 0.005 & 0.020 & 8.11E-01 & $9.56 \mathrm{E}-01$ & 0.000 \\
\hline & Caudate volume & -0.023 & 0.025 & 3.54E-01 & 6.95E-01 & 0.000 \\
\hline & Putamen volume & -0.046 & 0.025 & 7.11E-02 & 5.57E-01 & 0.001 \\
\hline & Thalamus volume & 0.009 & 0.022 & 6.38E-01 & 8.99E-01 & 0.000 \\
\hline \multirow{10}{*}{ SCZ (prior= 0.05) } & TBV & -0.028 & 0.025 & $2.66 \mathrm{E}-01$ & 6.73E-01 & 0.000 \\
\hline & Cortical GM & 0.009 & 0.015 & 5.33E-01 & 8.46E-01 & 0.000 \\
\hline & Total WM & -0.006 & 0.014 & 6.72E-01 & $9.12 \mathrm{E}-01$ & 0.000 \\
\hline & Subcortical GM & -0.002 & 0.018 & $9.17 \mathrm{E}-01$ & $9.98 \mathrm{E}-01$ & 0.000 \\
\hline & Total Ventricular volume & -0.039 & 0.027 & $1.54 \mathrm{E}-01$ & 6.73E-01 & 0.001 \\
\hline & Cerebellum volume & -0.021 & 0.023 & 3.67E-01 & 7.14E-01 & 0.000 \\
\hline & Amygdala-hippocampus complex & 0.024 & 0.020 & 2.88E-01 & 6.73E-01 & 0.000 \\
\hline & Caudate volume & -0.005 & 0.025 & 8.39E-01 & $9.66 \mathrm{E}-01$ & -0.001 \\
\hline & Putamen volume & -0.008 & 0.025 & 7.61E-01 & 9.30E-01 & -0.001 \\
\hline & Thalamus volume & 0.003 & 0.022 & 8.97E-01 & 9.98E-01 & 0.000 \\
\hline \multirow{10}{*}{ SCZ (prior= 0.1) } & TBV & -0.011 & 0.025 & 6.50E-01 & $9.00 \mathrm{E}-01$ & -0.001 \\
\hline & Cortical GM & 0.006 & 0.015 & 7.07E-01 & 9.23E-01 & 0.000 \\
\hline & Total WM & 0.004 & 0.014 & 7.63E-01 & $9.30 \mathrm{E}-01$ & 0.000 \\
\hline & Subcortical GM & 0.008 & 0.018 & 6.47E-01 & $9.00 \mathrm{E}-01$ & 0.000 \\
\hline & Total Ventricular volume & -0.034 & 0.027 & 2.07E-01 & 6.73E-01 & 0.000 \\
\hline & Cerebellum volume & -0.013 & 0.023 & 5.72E-01 & 8.68E-01 & 0.000 \\
\hline & Amygdala-hippocampus complex & 0.010 & 0.020 & $6.60 \mathrm{E}-01$ & $9.02 \mathrm{E}-01$ & 0.000 \\
\hline & Caudate volume & 0.001 & 0.025 & 9.75E-01 & 9.98E-01 & -0.001 \\
\hline & Putamen volume & 0.013 & 0.025 & 6.23E-01 & 8.90E-01 & 0.000 \\
\hline & Thalamus volume & 0.015 & 0.022 & 4.70E-01 & 7.84E-01 & 0.000 \\
\hline \multirow{6}{*}{$\mathrm{SCZ}($ prior $=0.5)$} & TBV & -0.008 & 0.025 & 7.44E-01 & $9.29 \mathrm{E}-01$ & -0.001 \\
\hline & Cortical GM & 0.012 & 0.015 & 4.02E-01 & $7.46 \mathrm{E}-01$ & 0.000 \\
\hline & Total WM & -0.005 & 0.014 & 7.12E-01 & $9.23 \mathrm{E}-01$ & 0.000 \\
\hline & Subcortical GM & 0.013 & 0.018 & 4.65E-01 & 7.84E-01 & 0.000 \\
\hline & Total Ventricular volume & -0.013 & 0.027 & 6.31E-01 & 8.95E-01 & -0.001 \\
\hline & Cerebellum volume & -0.005 & 0.023 & 8.22E-01 & $9.62 \mathrm{E}-01$ & -0.001 \\
\hline
\end{tabular}




\begin{tabular}{|c|c|c|c|c|c|c|}
\hline & Amygdala-hippocampus complex & 0.031 & 0.020 & $1.65 \mathrm{E}-01$ & 6.73E-01 & 0.000 \\
\hline & Caudate volume & -0.013 & 0.025 & 5.85E-01 & 8.75E-01 & 0.000 \\
\hline & Putamen volume & 0.028 & 0.025 & 2.72E-01 & 6.73E-01 & 0.000 \\
\hline & Thalamus volume & 0.010 & 0.022 & $6.08 \mathrm{E}-01$ & 8.90E-01 & 0.000 \\
\hline \multirow{10}{*}{ SCZ (prior= 1) } & TBV & -0.008 & 0.025 & 7.60E-01 & 9.30E-01 & -0.001 \\
\hline & Cortical GM & 0.009 & 0.015 & 5.59E-01 & $8.68 \mathrm{E}-01$ & 0.000 \\
\hline & Total WM & -0.006 & 0.014 & 6.83E-01 & $9.16 \mathrm{E}-01$ & 0.000 \\
\hline & Subcortical GM & -0.002 & 0.018 & 8.95E-01 & $9.98 \mathrm{E}-01$ & 0.000 \\
\hline & Total Ventricular volume & -0.017 & 0.027 & 5.29E-01 & 8.45E-01 & 0.000 \\
\hline & Cerebellum volume & -0.015 & 0.023 & 5.02E-01 & 8.14E-01 & 0.000 \\
\hline & Amygdala-hippocampus complex & 0.022 & 0.020 & 3.12E-01 & 6.73E-01 & 0.000 \\
\hline & Caudate volume & -0.028 & 0.025 & $2.56 \mathrm{E}-01$ & 6.73E-01 & 0.000 \\
\hline & Putamen volume & -0.001 & 0.025 & 9.65E-01 & $9.98 \mathrm{E}-01$ & -0.001 \\
\hline & Thalamus volume & 0.007 & 0.022 & 7.42E-01 & 9.29E-01 & 0.000 \\
\hline \multirow{10}{*}{ SCZ (Infinitesimal prior) } & TBV & -0.009 & 0.025 & $7.23 E-01$ & $9.24 \mathrm{E}-01$ & -0.001 \\
\hline & Cortical GM & -0.001 & 0.015 & $9.58 \mathrm{E}-01$ & $9.98 \mathrm{E}-01$ & 0.000 \\
\hline & Total WM & -0.016 & 0.014 & 2.62E-01 & 6.73E-01 & 0.000 \\
\hline & Subcortical GM & -0.001 & 0.018 & 9.38E-01 & $9.98 \mathrm{E}-01$ & 0.000 \\
\hline & Total Ventricular volume & -0.019 & 0.027 & 4.93E-01 & 8.06E-01 & 0.000 \\
\hline & Cerebellum volume & -0.005 & 0.023 & 8.27E-01 & 9.64E-01 & -0.001 \\
\hline & Amygdala-hippocampus complex & 0.029 & 0.020 & 1.82E-01 & 6.73E-01 & 0.000 \\
\hline & Caudate volume & -0.035 & 0.025 & $1.55 \mathrm{E}-01$ & $6.73 E-01$ & 0.001 \\
\hline & Putamen volume & 0.000 & 0.025 & $9.98 \mathrm{E}-01$ & $9.98 \mathrm{E}-01$ & -0.001 \\
\hline & Thalamus volume & 0.012 & 0.022 & 5.68E-01 & 8.68E-01 & 0.000 \\
\hline \multirow{10}{*}{$\mathrm{BD}($ prior $=0.01)$} & TBV & 0.029 & 0.025 & $2.42 \mathrm{E}-01$ & 6.73E-01 & 0.000 \\
\hline & Cortical GM & 0.017 & 0.015 & 2.57E-01 & 6.73E-01 & 0.000 \\
\hline & Total WM & -0.003 & 0.014 & 8.02E-01 & $9.49 \mathrm{E}-01$ & 0.000 \\
\hline & Subcortical GM & 0.014 & 0.018 & 4.46E-01 & $7.78 \mathrm{E}-01$ & 0.000 \\
\hline & Total Ventricular volume & -0.036 & 0.027 & $1.91 \mathrm{E}-01$ & 6.73E-01 & 0.001 \\
\hline & Cerebellum volume & -0.004 & 0.023 & 8.45E-01 & $9.70 \mathrm{E}-01$ & -0.001 \\
\hline & Amygdala-hippocampus complex & 0.022 & 0.020 & 3.18E-01 & $6.73 E-01$ & 0.000 \\
\hline & Caudate volume & -0.025 & 0.025 & 3.10E-01 & $6.73 \mathrm{E}-01$ & 0.000 \\
\hline & Putamen volume & 0.026 & 0.025 & 3.07E-01 & 6.73E-01 & 0.000 \\
\hline & Thalamus volume & 0.012 & 0.022 & 5.62E-01 & 8.68E-01 & 0.000 \\
\hline \multirow{6}{*}{$\mathrm{BD}($ prior $=0.05)$} & TBV & 0.018 & 0.025 & 4.64E-01 & $7.84 \mathrm{E}-01$ & 0.000 \\
\hline & Cortical GM & 0.018 & 0.015 & 2.10E-01 & 6.73E-01 & 0.000 \\
\hline & Total WM & -0.008 & 0.014 & 5.83E-01 & 8.74E-01 & 0.000 \\
\hline & Subcortical GM & 0.002 & 0.018 & $9.00 \mathrm{E}-01$ & $9.98 \mathrm{E}-01$ & 0.000 \\
\hline & Total Ventricular volume & -0.014 & 0.027 & $6.10 \mathrm{E}-01$ & 8.90E-01 & -0.001 \\
\hline & Cerebellum volume & -0.001 & 0.023 & $9.80 \mathrm{E}-01$ & 9.98E-01 & -0.001 \\
\hline
\end{tabular}




\begin{tabular}{|c|c|c|c|c|c|c|}
\hline & Amygdala-hippocampus complex & 0.027 & 0.020 & 2.23E-01 & 6.73E-01 & 0.000 \\
\hline & Caudate volume & -0.026 & 0.025 & $2.88 \mathrm{E}-01$ & 6.73E-01 & 0.000 \\
\hline & Putamen volume & -0.001 & 0.025 & 9.67E-01 & $9.98 \mathrm{E}-01$ & -0.001 \\
\hline & Thalamus volume & 0.008 & 0.022 & 6.96E-01 & 9.23E-01 & 0.000 \\
\hline \multirow{10}{*}{$\mathrm{BD}($ prior $=0.1)$} & TBV & 0.014 & 0.025 & 5.77E-01 & 8.68E-01 & 0.000 \\
\hline & Cortical GM & 0.017 & 0.015 & 2.50E-01 & 6.73E-01 & 0.000 \\
\hline & Total WM & -0.009 & 0.014 & 5.35E-01 & $8.46 \mathrm{E}-01$ & 0.000 \\
\hline & Subcortical GM & -0.001 & 0.018 & $9.56 \mathrm{E}-01$ & $9.98 \mathrm{E}-01$ & 0.000 \\
\hline & Total Ventricular volume & -0.009 & 0.027 & 7.42E-01 & $9.29 \mathrm{E}-01$ & -0.001 \\
\hline & Cerebellum volume & -0.002 & 0.023 & $9.44 \mathrm{E}-01$ & $9.98 \mathrm{E}-01$ & -0.001 \\
\hline & Amygdala-hippocampus complex & 0.028 & 0.020 & 2.11E-01 & 6.73E-01 & 0.000 \\
\hline & Caudate volume & -0.026 & 0.025 & 2.97E-01 & 6.73E-01 & 0.000 \\
\hline & Putamen volume & -0.009 & 0.025 & 7.37E-01 & $9.29 \mathrm{E}-01$ & -0.001 \\
\hline & Thalamus volume & 0.006 & 0.022 & 7.58E-01 & 9.30E-01 & 0.000 \\
\hline \multirow{10}{*}{$\mathrm{BD}$ (prior= 0.5) } & TBV & 0.010 & 0.025 & 6.94E-01 & 9.23E-01 & -0.001 \\
\hline & Cortical GM & 0.015 & 0.015 & 2.96E-01 & 6.73E-01 & 0.000 \\
\hline & Total WM & -0.009 & 0.014 & 4.97E-01 & 8.10E-01 & 0.000 \\
\hline & Subcortical GM & -0.002 & 0.018 & $9.01 \mathrm{E}-01$ & 9.98E-01 & 0.000 \\
\hline & Total Ventricular volume & -0.004 & 0.027 & 8.95E-01 & 9.98E-01 & -0.001 \\
\hline & Cerebellum volume & -0.001 & 0.023 & $9.58 \mathrm{E}-01$ & $9.98 \mathrm{E}-01$ & -0.001 \\
\hline & Amygdala-hippocampus complex & 0.029 & 0.020 & 1.95E-01 & 6.73E-01 & 0.000 \\
\hline & Caudate volume & -0.024 & 0.025 & 3.36E-01 & 6.91E-01 & 0.000 \\
\hline & Putamen volume & -0.013 & 0.025 & 6.23E-01 & 8.90E-01 & 0.000 \\
\hline & Thalamus volume & 0.006 & 0.022 & 7.83E-01 & 9.44E-01 & 0.000 \\
\hline \multirow{10}{*}{$\mathrm{BD}($ prior$=1)$} & TBV & 0.009 & 0.025 & 7.07E-01 & $9.23 \mathrm{E}-01$ & -0.001 \\
\hline & Cortical GM & 0.015 & 0.015 & 3.04E-01 & 6.73E-01 & 0.000 \\
\hline & Total WM & -0.010 & 0.014 & 4.92E-01 & 8.06E-01 & 0.000 \\
\hline & Subcortical GM & -0.003 & 0.018 & 8.89E-01 & $9.98 \mathrm{E}-01$ & 0.000 \\
\hline & Total Ventricular volume & -0.003 & 0.027 & 9.17E-01 & $9.98 \mathrm{E}-01$ & -0.001 \\
\hline & Cerebellum volume & -0.002 & 0.023 & 9.47E-01 & $9.98 \mathrm{E}-01$ & -0.001 \\
\hline & Amygdala-hippocampus complex & 0.029 & 0.020 & $1.94 \mathrm{E}-01$ & 6.73E-01 & 0.000 \\
\hline & Caudate volume & -0.023 & 0.025 & $3.44 \mathrm{E}-01$ & 6.91E-01 & 0.000 \\
\hline & Putamen volume & -0.013 & 0.025 & $6.06 \mathrm{E}-01$ & 8.90E-01 & 0.000 \\
\hline & Thalamus volume & 0.005 & 0.022 & 7.93E-01 & 9.46E-01 & 0.000 \\
\hline \multirow{3}{*}{ BD (Infinitesimal prior) } & TBV & 0.000 & 0.025 & 9.90E-01 & $9.98 \mathrm{E}-01$ & -0.001 \\
\hline & Cortical GM & 0.018 & 0.015 & 2.23E-01 & 6.73E-01 & 0.000 \\
\hline & Total WM & -0.011 & 0.014 & 4.43E-01 & 7.78E-01 & 0.000 \\
\hline
\end{tabular}




\begin{tabular}{|c|c|c|c|c|c|c|}
\hline & Subcortical GM & 0.009 & 0.018 & $6.38 \mathrm{E}-01$ & 8.99E-01 & 0.000 \\
\hline & Total Ventricular volume & -0.016 & 0.027 & $5.66 \mathrm{E}-01$ & 8.68E-01 & -0.001 \\
\hline & Cerebellum volume & 0.006 & 0.023 & 7.87E-01 & $9.44 \mathrm{E}-01$ & 0.000 \\
\hline & Amygdala-hippocampus complex & 0.040 & 0.020 & 7.29E-02 & 5.57E-01 & 0.001 \\
\hline & Caudate volume & -0.024 & 0.025 & 3.37E-01 & 6.91E-01 & 0.000 \\
\hline & Putamen volume & 0.013 & 0.025 & 6.23E-01 & 8.90E-01 & 0.000 \\
\hline & Thalamus volume & 0.004 & 0.022 & 8.38E-01 & 9.66E-01 & 0.000 \\
\hline \multirow{10}{*}{ MDD (prior $=0.01)$} & TBV & -0.030 & 0.025 & 2.31E-01 & 6.73E-01 & 0.000 \\
\hline & Cortical GM & 0.000 & 0.015 & $9.81 \mathrm{E}-01$ & $9.98 \mathrm{E}-01$ & 0.000 \\
\hline & Total WM & -0.028 & 0.014 & $4.31 \mathrm{E}-02 *$ & 4.64E-01 & 0.001 \\
\hline & Subcortical GM & -0.030 & 0.018 & $1.00 \mathrm{E}-01$ & 6.23E-01 & 0.001 \\
\hline & Total Ventricular volume & -0.010 & 0.027 & 7.24E-01 & $9.24 \mathrm{E}-01$ & -0.001 \\
\hline & Cerebellum volume & -0.015 & 0.023 & $5.26 \mathrm{E}-01$ & 8.42E-01 & 0.000 \\
\hline & Amygdala-hippocampus complex & 0.011 & 0.020 & 6.27E-01 & 8.93E-01 & 0.000 \\
\hline & Caudate volume & -0.030 & 0.026 & 2.18E-01 & 6.73E-01 & 0.000 \\
\hline & Putamen volume & -0.010 & 0.025 & 6.85E-01 & 9.16E-01 & -0.001 \\
\hline & Thalamus volume & -0.052 & 0.022 & $9.41 \mathrm{E}-03 *$ & 2.21E-01 & 0.002 \\
\hline \multirow{10}{*}{ MDD (prior $=0.05$ ) } & TBV & -0.059 & 0.025 & $1.87 \mathrm{E}-02 *$ & 2.92E-01 & 0.003 \\
\hline & Cortical GM & -0.008 & 0.015 & 5.90E-01 & 8.78E-01 & 0.000 \\
\hline & Total WM & -0.016 & 0.014 & 2.45E-01 & 6.73E-01 & 0.000 \\
\hline & Subcortical GM & -0.035 & 0.018 & 5.69E-02 & $5.04 \mathrm{E}-01$ & 0.001 \\
\hline & Total Ventricular volume & 0.007 & 0.028 & 7.86E-01 & 9.44E-01 & -0.001 \\
\hline & Cerebellum volume & -0.038 & 0.023 & 1.03E-01 & $6.28 \mathrm{E}-01$ & 0.001 \\
\hline & Amygdala-hippocampus complex & -0.008 & 0.020 & $7.08 \mathrm{E}-01$ & 9.23E-01 & 0.000 \\
\hline & Caudate volume & -0.044 & 0.026 & $7.58 \mathrm{E}-02$ & 5.61E-01 & 0.001 \\
\hline & Putamen volume & -0.034 & 0.025 & $1.82 \mathrm{E}-01$ & 6.73E-01 & 0.001 \\
\hline & Thalamus volume & -0.022 & 0.022 & 2.87E-01 & 6.73E-01 & 0.000 \\
\hline \multirow{10}{*}{ MDD (prior= 0.1 ) } & TBV & -0.060 & 0.025 & $1.78 \mathrm{E}-02 *$ & 2.92E-01 & 0.003 \\
\hline & Cortical GM & -0.010 & 0.015 & 4.90E-01 & 8.06E-01 & 0.000 \\
\hline & Total WM & -0.015 & 0.014 & 2.74E-01 & 6.73E-01 & 0.000 \\
\hline & Subcortical GM & -0.035 & 0.018 & 5.52E-02 & 5.04E-01 & 0.001 \\
\hline & Total Ventricular volume & 0.007 & 0.028 & 8.13E-01 & 9.57E-01 & -0.001 \\
\hline & Cerebellum volume & -0.042 & 0.023 & 7.27E-02 & 5.57E-01 & 0.001 \\
\hline & Amygdala-hippocampus complex & -0.009 & 0.020 & 7.01E-01 & 9.23E-01 & 0.000 \\
\hline & Caudate volume & -0.041 & 0.026 & $1.01 \mathrm{E}-01$ & $6.23 \mathrm{E}-01$ & 0.001 \\
\hline & Putamen volume & -0.036 & 0.025 & $1.61 \mathrm{E}-01$ & 6.73E-01 & 0.001 \\
\hline & Thalamus volume & -0.022 & 0.022 & 2.82E-01 & 6.73E-01 & 0.000 \\
\hline MDD (prior $=0.5$ ) & TBV & -0.056 & 0.025 & $2.57 \mathrm{E}-02 *$ & 3.39E-01 & 0.003 \\
\hline
\end{tabular}




\begin{tabular}{|c|c|c|c|c|c|c|}
\hline & Cortical GM & -0.012 & 0.015 & 4.28E-01 & 7.68E-01 & 0.000 \\
\hline & Total WM & -0.012 & 0.014 & 3.90E-01 & 7.42E-01 & 0.000 \\
\hline & Subcortical GM & -0.032 & 0.018 & 7.86E-02 & 5.61E-01 & 0.001 \\
\hline & Total Ventricular volume & 0.003 & 0.027 & 9.13E-01 & 9.98E-01 & -0.001 \\
\hline & Cerebellum volume & -0.047 & 0.023 & 4.17E-02* & 4.61E-01 & 0.002 \\
\hline & Amygdala-hippocampus complex & -0.007 & 0.020 & 7.60E-01 & 9.30E-01 & 0.000 \\
\hline & Caudate volume & -0.035 & 0.026 & $1.60 \mathrm{E}-01$ & 6.73E-01 & 0.001 \\
\hline & Putamen volume & -0.037 & 0.025 & $1.50 \mathrm{E}-01$ & 6.73E-01 & 0.001 \\
\hline & Thalamus volume & -0.020 & 0.022 & 3.32E-01 & 6.91E-01 & 0.000 \\
\hline \multirow{10}{*}{ MDD (prior= 1) } & TBV & -0.056 & 0.025 & $2.73 \mathrm{E}-02 *$ & $3.48 \mathrm{E}-01$ & 0.002 \\
\hline & Cortical GM & -0.012 & 0.015 & 4.20E-01 & 7.59E-01 & 0.000 \\
\hline & Total WM & -0.012 & 0.014 & 4.05E-01 & 7.46E-01 & 0.000 \\
\hline & Subcortical GM & -0.032 & 0.018 & 7.89E-02 & $5.61 \mathrm{E}-01$ & 0.001 \\
\hline & Total Ventricular volume & 0.003 & 0.027 & $9.15 \mathrm{E}-01$ & $9.98 \mathrm{E}-01$ & -0.001 \\
\hline & Cerebellum volume & -0.048 & 0.023 & $3.98 \mathrm{E}-02 *$ & 4.52E-01 & 0.002 \\
\hline & Amygdala-hippocampus complex & -0.007 & 0.020 & 7.64E-01 & $9.30 \mathrm{E}-01$ & 0.000 \\
\hline & Caudate volume & -0.034 & 0.026 & $1.65 \mathrm{E}-01$ & 6.73E-01 & 0.001 \\
\hline & Putamen volume & -0.037 & 0.025 & 1.43E-01 & 6.73E-01 & 0.001 \\
\hline & Thalamus volume & -0.020 & 0.022 & 3.36E-01 & $6.91 \mathrm{E}-01$ & 0.000 \\
\hline \multirow{10}{*}{ MDD (Infinitesimal prior) } & TBV & -0.066 & 0.025 & 8.78E-03* & $2.21 \mathrm{E}-01$ & 0.004 \\
\hline & Cortical GM & -0.006 & 0.015 & 6.73E-01 & $9.12 \mathrm{E}-01$ & 0.000 \\
\hline & Total WM & -0.019 & 0.014 & $1.85 \mathrm{E}-01$ & 6.73E-01 & 0.000 \\
\hline & Subcortical GM & -0.034 & 0.018 & 6.22E-02 & $5.21 \mathrm{E}-01$ & 0.001 \\
\hline & Total Ventricular volume & 0.022 & 0.027 & 4.33E-01 & $7.71 \mathrm{E}-01$ & 0.000 \\
\hline & Cerebellum volume & -0.037 & 0.023 & 1.09E-01 & 6.30E-01 & 0.001 \\
\hline & Amygdala-hippocampus complex & 0.000 & 0.020 & 9.93E-01 & 9.98E-01 & 0.000 \\
\hline & Caudate volume & -0.028 & 0.026 & 2.56E-01 & 6.73E-01 & 0.000 \\
\hline & Putamen volume & -0.040 & 0.025 & $1.22 \mathrm{E}-01$ & $6.66 \mathrm{E}-01$ & 0.001 \\
\hline & Thalamus volume & -0.029 & 0.022 & 1.49E-01 & 6.73E-01 & 0.000 \\
\hline \multirow{9}{*}{$\mathrm{ADHD}$ (prior= 0.01) } & TBV & -0.033 & 0.025 & $1.94 \mathrm{E}-01$ & $6.73 \mathrm{E}-01$ & 0.000 \\
\hline & Cortical GM & -0.007 & 0.015 & $6.49 \mathrm{E}-01$ & $9.00 \mathrm{E}-01$ & 0.000 \\
\hline & Total WM & 0.018 & 0.014 & 1.93E-01 & 6.73E-01 & 0.000 \\
\hline & Subcortical GM & -0.027 & 0.018 & 1.34E-01 & 6.73E-01 & 0.000 \\
\hline & Total Ventricular volume & -0.030 & 0.027 & 2.81E-01 & 6.73E-01 & 0.000 \\
\hline & Cerebellum volume & -0.029 & 0.023 & 2.10E-01 & 6.73E-01 & 0.000 \\
\hline & Amygdala-hippocampus complex & 0.014 & 0.020 & 5.16E-01 & 8.30E-01 & 0.000 \\
\hline & Caudate volume & -0.083 & 0.026 & 7.49E-04* & $3.15 \mathrm{E}-02 *$ & 0.006 \\
\hline & Putamen volume & -0.037 & 0.025 & $1.53 \mathrm{E}-01$ & 6.73E-01 & 0.001 \\
\hline
\end{tabular}




\begin{tabular}{|c|c|c|c|c|c|c|}
\hline & Thalamus volume & -0.001 & 0.022 & 9.53E-01 & 9.98E-01 & 0.000 \\
\hline \multirow{10}{*}{ ADHD (prior= 0.05) } & TBV & -0.053 & 0.025 & $3.54 \mathrm{E}-02 *$ & 4.13E-01 & 0.002 \\
\hline & Cortical GM & -0.014 & 0.015 & 3.50E-01 & 6.95E-01 & 0.000 \\
\hline & Total WM & 0.015 & 0.014 & 2.92E-01 & 6.73E-01 & 0.000 \\
\hline & Subcortical GM & -0.021 & 0.018 & $2.50 \mathrm{E}-01$ & 6.73E-01 & 0.000 \\
\hline & Total Ventricular volume & -0.023 & 0.027 & 4.09E-01 & 7.50E-01 & 0.000 \\
\hline & Cerebellum volume & -0.036 & 0.023 & 1.19E-01 & 6.59E-01 & 0.001 \\
\hline & Amygdala-hippocampus complex & 0.005 & 0.020 & 8.17E-01 & $9.58 \mathrm{E}-01$ & 0.000 \\
\hline & Caudate volume & -0.061 & 0.026 & $1.30 \mathrm{E}-02 *$ & $2.52 \mathrm{E}-01$ & 0.003 \\
\hline & Putamen volume & -0.025 & 0.025 & $3.24 \mathrm{E}-01$ & 6.79E-01 & 0.000 \\
\hline & Thalamus volume & 0.000 & 0.022 & 9.93E-01 & 9.98E-01 & 0.000 \\
\hline \multirow{10}{*}{ ADHD (prior= 0.1) } & TBV & -0.055 & 0.025 & $3.00 \mathrm{E}-02 *$ & $3.60 \mathrm{E}-01$ & 0.002 \\
\hline & Cortical GM & -0.016 & 0.015 & $2.84 \mathrm{E}-01$ & 6.73E-01 & 0.000 \\
\hline & Total WM & 0.014 & 0.014 & 3.19E-01 & 6.73E-01 & 0.000 \\
\hline & Subcortical GM & -0.019 & 0.018 & $2.86 \mathrm{E}-01$ & 6.73E-01 & 0.000 \\
\hline & Total Ventricular volume & -0.016 & 0.027 & 5.56E-01 & 8.68E-01 & 0.000 \\
\hline & Cerebellum volume & -0.037 & 0.023 & 1.06E-01 & 6.30E-01 & 0.001 \\
\hline & Amygdala-hippocampus complex & 0.005 & 0.020 & 8.29E-01 & 9.64E-01 & 0.000 \\
\hline & Caudate volume & -0.055 & 0.026 & $2.58 \mathrm{E}-02 *$ & 3.39E-01 & 0.002 \\
\hline & Putamen volume & -0.024 & 0.025 & $3.41 \mathrm{E}-01$ & 6.91E-01 & 0.000 \\
\hline & Thalamus volume & -0.001 & 0.022 & 9.67E-01 & 9.98E-01 & 0.000 \\
\hline \multirow{10}{*}{ ADHD (prior= 0.5) } & TBV & -0.058 & 0.025 & $2.02 \mathrm{E}-02 *$ & 2.92E-01 & 0.003 \\
\hline & Cortical GM & -0.016 & 0.015 & 2.85E-01 & 6.73E-01 & 0.000 \\
\hline & Total WM & 0.012 & 0.014 & 3.98E-01 & 7.46E-01 & 0.000 \\
\hline & Subcortical GM & -0.020 & 0.018 & 2.64E-01 & 6.73E-01 & 0.000 \\
\hline & Total Ventricular volume & -0.008 & 0.027 & 7.71E-01 & 9.36E-01 & -0.001 \\
\hline & Cerebellum volume & -0.038 & 0.023 & $1.01 \mathrm{E}-01$ & 6.23E-01 & 0.001 \\
\hline & Amygdala-hippocampus complex & 0.001 & 0.020 & $9.60 \mathrm{E}-01$ & 9.98E-01 & 0.000 \\
\hline & Caudate volume & -0.049 & 0.026 & 4.72E-02* & 4.72E-01 & 0.002 \\
\hline & Putamen volume & -0.026 & 0.025 & 3.11E-01 & 6.73E-01 & 0.000 \\
\hline & Thalamus volume & -0.003 & 0.022 & 8.71E-01 & 9.93E-01 & 0.000 \\
\hline \multirow{6}{*}{ ADHD (prior= 1) } & TBV & -0.059 & 0.025 & $2.01 \mathrm{E}-02 *$ & $2.92 \mathrm{E}-01$ & 0.003 \\
\hline & Cortical GM & -0.016 & 0.015 & $2.88 \mathrm{E}-01$ & 6.73E-01 & 0.000 \\
\hline & Total WM & 0.012 & 0.014 & 4.01E-01 & $7.46 \mathrm{E}-01$ & 0.000 \\
\hline & Subcortical GM & -0.020 & 0.018 & $2.70 \mathrm{E}-01$ & 6.73E-01 & 0.000 \\
\hline & Total Ventricular volume & -0.007 & 0.027 & 7.88E-01 & $9.44 \mathrm{E}-01$ & -0.001 \\
\hline & Cerebellum volume & -0.038 & 0.023 & 9.69E-02 & 6.23E-01 & 0.001 \\
\hline
\end{tabular}




\begin{tabular}{|c|c|c|c|c|c|c|}
\hline & Amygdala-hippocampus complex & 0.001 & 0.020 & 9.70E-01 & $9.98 \mathrm{E}-01$ & 0.000 \\
\hline & Caudate volume & -0.048 & 0.025 & 5.26E-02 & 5.02E-01 & 0.002 \\
\hline & Putamen volume & -0.026 & 0.025 & 3.12E-01 & 6.73E-01 & 0.000 \\
\hline & Thalamus volume & -0.003 & 0.022 & 8.77E-01 & 9.93E-01 & 0.000 \\
\hline \multirow{10}{*}{ ADHD (Infinitesimal prior) } & TBV & -0.069 & 0.025 & $5.98 \mathrm{E}-03^{*}$ & 1.93E-01 & 0.004 \\
\hline & Cortical GM & -0.018 & 0.015 & $2.11 \mathrm{E}-01$ & 6.73E-01 & 0.000 \\
\hline & Total WM & 0.008 & 0.014 & 5.43E-01 & 8.51E-01 & 0.000 \\
\hline & Subcortical GM & -0.023 & 0.018 & $2.04 \mathrm{E}-01$ & 6.73E-01 & 0.000 \\
\hline & Total Ventricular volume & 0.004 & 0.027 & 8.82E-01 & 9.96E-01 & -0.001 \\
\hline & Cerebellum volume & -0.019 & 0.023 & 4.11E-01 & $7.50 \mathrm{E}-01$ & 0.000 \\
\hline & Amygdala-hippocampus complex & -0.002 & 0.020 & $9.26 \mathrm{E}-01$ & 9.98E-01 & 0.000 \\
\hline & Caudate volume & -0.058 & 0.026 & $1.91 \mathrm{E}-02 *$ & 2.92E-01 & 0.003 \\
\hline & Putamen volume & -0.029 & 0.025 & 2.61E-01 & 6.73E-01 & 0.000 \\
\hline & Thalamus volume & -0.002 & 0.022 & 9.17E-01 & $9.98 \mathrm{E}-01$ & 0.000 \\
\hline \multirow{10}{*}{ ASD (prior= 0.01 ) } & TBV & 0.048 & 0.025 & 5.62E-02 & $5.04 \mathrm{E}-01$ & 0.002 \\
\hline & Cortical GM & -0.005 & 0.015 & 7.48E-01 & 9.29E-01 & 0.000 \\
\hline & Total WM & 0.000 & 0.014 & $9.96 \mathrm{E}-01$ & $9.98 \mathrm{E}-01$ & 0.000 \\
\hline & Subcortical GM & 0.007 & 0.018 & 6.81E-01 & $9.16 \mathrm{E}-01$ & 0.000 \\
\hline & Total Ventricular volume & 0.028 & 0.027 & 3.15E-01 & 6.73E-01 & 0.000 \\
\hline & Cerebellum volume & -0.013 & 0.023 & 5.75E-01 & 8.68E-01 & 0.000 \\
\hline & Amygdala-hippocampus complex & -0.019 & 0.020 & 3.94E-01 & 7.42E-01 & 0.000 \\
\hline & Caudate volume & -0.014 & 0.025 & 5.62E-01 & 8.68E-01 & 0.000 \\
\hline & Putamen volume & 0.037 & 0.025 & 1.43E-01 & 6.73E-01 & 0.001 \\
\hline & Thalamus volume & 0.019 & 0.022 & 3.37E-01 & 6.91E-01 & 0.000 \\
\hline \multirow{10}{*}{ ASD (prior $=0.05$ ) } & TBV & 0.063 & 0.025 & $1.25 \mathrm{E}-02 *$ & $2.52 \mathrm{E}-01$ & 0.003 \\
\hline & Cortical GM & -0.005 & 0.015 & 7.28E-01 & $9.24 \mathrm{E}-01$ & 0.000 \\
\hline & Total WM & 0.006 & 0.014 & $6.70 \mathrm{E}-01$ & $9.12 \mathrm{E}-01$ & 0.000 \\
\hline & Subcortical GM & 0.013 & 0.018 & 4.88E-01 & 8.06E-01 & 0.000 \\
\hline & Total Ventricular volume & 0.033 & 0.027 & 2.35E-01 & 6.73E-01 & 0.000 \\
\hline & Cerebellum volume & -0.003 & 0.023 & 8.93E-01 & $9.98 \mathrm{E}-01$ & -0.001 \\
\hline & Amygdala-hippocampus complex & -0.011 & 0.020 & 6.05E-01 & 8.90E-01 & 0.000 \\
\hline & Caudate volume & -0.009 & 0.026 & 7.02E-01 & 9.23E-01 & -0.001 \\
\hline & Putamen volume & 0.035 & 0.025 & $1.76 \mathrm{E}-01$ & 6.73E-01 & 0.001 \\
\hline & Thalamus volume & 0.022 & 0.022 & 2.71E-01 & 6.73E-01 & 0.000 \\
\hline \multirow{4}{*}{ ASD (prior $=0.1)$} & TBV & 0.065 & 0.025 & 9.46E-03* & $2.21 \mathrm{E}-01$ & 0.004 \\
\hline & Cortical GM & -0.005 & 0.015 & 7.18E-01 & $9.24 \mathrm{E}-01$ & 0.000 \\
\hline & Total WM & 0.006 & 0.014 & $6.49 \mathrm{E}-01$ & $9.00 \mathrm{E}-01$ & 0.000 \\
\hline & Subcortical GM & 0.013 & 0.018 & 4.75E-01 & 7.89E-01 & 0.000 \\
\hline
\end{tabular}




\begin{tabular}{|c|c|c|c|c|c|c|}
\hline & Total Ventricular volume & 0.034 & 0.027 & 2.16E-01 & 6.73E-01 & 0.000 \\
\hline & Cerebellum volume & -0.001 & 0.023 & $9.58 \mathrm{E}-01$ & $9.98 \mathrm{E}-01$ & -0.001 \\
\hline & Amygdala-hippocampus complex & -0.011 & 0.020 & 6.17E-01 & 8.90E-01 & 0.000 \\
\hline & Caudate volume & -0.008 & 0.026 & 7.32E-01 & $9.25 \mathrm{E}-01$ & -0.001 \\
\hline & Putamen volume & 0.034 & 0.025 & $1.86 \mathrm{E}-01$ & 6.73E-01 & 0.000 \\
\hline & Thalamus volume & 0.022 & 0.022 & 2.74E-01 & 6.73E-01 & 0.000 \\
\hline \multirow{10}{*}{ ASD (prior= 0.5) } & TBV & 0.067 & 0.025 & 7.89E-03* & $2.21 \mathrm{E}-01$ & 0.004 \\
\hline & Cortical GM & -0.005 & 0.015 & $7.26 \mathrm{E}-01$ & $9.24 \mathrm{E}-01$ & 0.000 \\
\hline & Total WM & 0.007 & 0.014 & 6.22E-01 & 8.90E-01 & 0.000 \\
\hline & Subcortical GM & 0.013 & 0.018 & 4.59E-01 & 7.84E-01 & 0.000 \\
\hline & Total Ventricular volume & 0.034 & 0.027 & 2.14E-01 & 6.73E-01 & 0.000 \\
\hline & Cerebellum volume & 0.000 & 0.023 & 9.97E-01 & 9.98E-01 & -0.001 \\
\hline & Amygdala-hippocampus complex & -0.010 & 0.020 & $6.50 \mathrm{E}-01$ & $9.00 \mathrm{E}-01$ & 0.000 \\
\hline & Caudate volume & -0.008 & 0.026 & $7.50 \mathrm{E}-01$ & 9.29E-01 & -0.001 \\
\hline & Putamen volume & 0.033 & 0.025 & 1.96E-01 & 6.73E-01 & 0.000 \\
\hline & Thalamus volume & 0.022 & 0.022 & 2.72E-01 & 6.73E-01 & 0.000 \\
\hline \multirow{10}{*}{ ASD (prior= 1) } & TBV & 0.067 & 0.025 & 7.75E-03* & $2.21 \mathrm{E}-01$ & 0.004 \\
\hline & Cortical GM & -0.005 & 0.015 & 7.27E-01 & $9.24 \mathrm{E}-01$ & 0.000 \\
\hline & Total WM & 0.007 & 0.014 & 6.19E-01 & 8.90E-01 & 0.000 \\
\hline & Subcortical GM & 0.014 & 0.018 & 4.58E-01 & 7.84E-01 & 0.000 \\
\hline & Total Ventricular volume & 0.034 & 0.027 & 2.12E-01 & 6.73E-01 & 0.000 \\
\hline & Cerebellum volume & 0.000 & 0.023 & 9.98E-01 & 9.98E-01 & -0.001 \\
\hline & Amygdala-hippocampus complex & -0.010 & 0.020 & 6.54E-01 & $9.00 \mathrm{E}-01$ & 0.000 \\
\hline & Caudate volume & -0.008 & 0.026 & 7.50E-01 & 9.29E-01 & -0.001 \\
\hline & Putamen volume & 0.033 & 0.025 & $1.96 \mathrm{E}-01$ & 6.73E-01 & 0.000 \\
\hline & Thalamus volume & 0.022 & 0.022 & 2.73E-01 & 6.73E-01 & 0.000 \\
\hline \multirow{10}{*}{ ASD (Infinitesimal prior) } & TBV & 0.050 & 0.025 & $4.89 \mathrm{E}-02 *$ & $4.78 \mathrm{E}-01$ & 0.002 \\
\hline & Cortical GM & -0.008 & 0.015 & 5.94E-01 & 8.82E-01 & 0.000 \\
\hline & Total WM & -0.001 & 0.014 & 9.32E-01 & 9.98E-01 & 0.000 \\
\hline & Subcortical GM & 0.013 & 0.018 & 4.59E-01 & 7.84E-01 & 0.000 \\
\hline & Total Ventricular volume & 0.034 & 0.027 & 2.19E-01 & 6.73E-01 & 0.000 \\
\hline & Cerebellum volume & 0.004 & 0.023 & 8.75E-01 & 9.93E-01 & -0.001 \\
\hline & Amygdala-hippocampus complex & -0.012 & 0.020 & 5.74E-01 & 8.68E-01 & 0.000 \\
\hline & Caudate volume & -0.007 & 0.025 & 7.89E-01 & $9.44 \mathrm{E}-01$ & -0.001 \\
\hline & Putamen volume & 0.031 & 0.025 & 2.24E-01 & 6.73E-01 & 0.000 \\
\hline & Thalamus volume & 0.027 & 0.022 & 1.79E-01 & 6.73E-01 & 0.000 \\
\hline \multirow{2}{*}{ EA (prior $=0.01)$} & TBV & 0.087 & 0.025 & 4.98E-04* & $2.44 \mathrm{E}-02 *$ & 0.007 \\
\hline & Cortical GM & 0.009 & 0.015 & 5.43E-01 & 8.51E-01 & 0.000 \\
\hline
\end{tabular}




\begin{tabular}{|c|c|c|c|c|c|c|}
\hline & Total WM & 0.000 & 0.014 & $9.78 \mathrm{E}-01$ & 9.98E-01 & 0.000 \\
\hline & Subcortical GM & 0.001 & 0.018 & 9.54E-01 & 9.98E-01 & 0.000 \\
\hline & Total Ventricular volume & 0.012 & 0.027 & $6.56 \mathrm{E}-01$ & $9.00 \mathrm{E}-01$ & -0.001 \\
\hline & Cerebellum volume & 0.022 & 0.023 & 3.43E-01 & 6.91E-01 & 0.000 \\
\hline & Amygdala-hippocampus complex & -0.008 & 0.020 & 7.11E-01 & 9.23E-01 & 0.000 \\
\hline & Caudate volume & -0.009 & 0.026 & 7.05E-01 & 9.23E-01 & -0.001 \\
\hline & Putamen volume & -0.026 & 0.025 & 3.17E-01 & 6.73E-01 & 0.000 \\
\hline & Thalamus volume & 0.015 & 0.022 & 4.52E-01 & 7.84E-01 & 0.000 \\
\hline \multirow{10}{*}{ EA (prior $=0.05)$} & TBV & 0.031 & 0.025 & $2.20 \mathrm{E}-01$ & $6.73 \mathrm{E}-01$ & 0.000 \\
\hline & Cortical GM & 0.007 & 0.015 & $6.55 \mathrm{E}-01$ & $9.00 \mathrm{E}-01$ & 0.000 \\
\hline & Total WM & 0.001 & 0.014 & 9.59E-01 & 9.98E-01 & 0.000 \\
\hline & Subcortical GM & 0.036 & 0.018 & $4.62 \mathrm{E}-02 *$ & 4.72E-01 & 0.001 \\
\hline & Total Ventricular volume & 0.026 & 0.027 & 3.43E-01 & 6.91E-01 & 0.000 \\
\hline & Cerebellum volume & 0.037 & 0.023 & 1.13E-01 & 6.30E-01 & 0.001 \\
\hline & Amygdala-hippocampus complex & -0.002 & 0.020 & 9.12E-01 & 9.98E-01 & 0.000 \\
\hline & Caudate volume & 0.039 & 0.025 & 1.10E-01 & $6.30 \mathrm{E}-01$ & 0.001 \\
\hline & Putamen volume & 0.062 & 0.025 & $1.55 \mathrm{E}-02 *$ & 2.84E-01 & 0.003 \\
\hline & Thalamus volume & 0.022 & 0.022 & 2.80E-01 & 6.73E-01 & 0.000 \\
\hline \multirow{10}{*}{ EA (prior= 0.1) } & TBV & 0.134 & 0.025 & $9.36 \mathrm{E}-08 *$ & $1.35 \mathrm{E}-05^{*}$ & 0.017 \\
\hline & Cortical GM & 0.011 & 0.015 & 4.67E-01 & 7.84E-01 & 0.000 \\
\hline & Total WM & -0.023 & 0.014 & 1.11E-01 & 6.30E-01 & 0.000 \\
\hline & Subcortical GM & 0.025 & 0.018 & $1.84 \mathrm{E}-01$ & 6.73E-01 & 0.000 \\
\hline & Total Ventricular volume & 0.025 & 0.028 & 3.76E-01 & 7.27E-01 & 0.000 \\
\hline & Cerebellum volume & 0.047 & 0.023 & 4.66E-02* & 4.72E-01 & 0.002 \\
\hline & Amygdala-hippocampus complex & -0.028 & 0.020 & 2.21E-01 & 6.73E-01 & 0.000 \\
\hline & Caudate volume & 0.032 & 0.026 & 1.98E-01 & 6.73E-01 & 0.000 \\
\hline & Putamen volume & 0.023 & 0.025 & 3.81E-01 & 7.31E-01 & 0.000 \\
\hline & Thalamus volume & 0.045 & 0.023 & $2.88 \mathrm{E}-02 *$ & 3.55E-01 & 0.002 \\
\hline \multirow{10}{*}{ EA (prior $=0.5$ ) } & TBV & 0.135 & 0.025 & 7.12E-08* & $1.35 \mathrm{E}-05^{*}$ & 0.018 \\
\hline & Cortical GM & 0.012 & 0.015 & 4.42E-01 & 7.78E-01 & 0.000 \\
\hline & Total WM & -0.016 & 0.014 & 2.45E-01 & 6.73E-01 & 0.000 \\
\hline & Subcortical GM & 0.026 & 0.018 & 1.61E-01 & 6.73E-01 & 0.000 \\
\hline & Total Ventricular volume & 0.030 & 0.028 & 2.80E-01 & 6.73E-01 & 0.000 \\
\hline & Cerebellum volume & 0.045 & 0.023 & 5.76E-02 & 5.04E-01 & 0.001 \\
\hline & Amygdala-hippocampus complex & -0.032 & 0.020 & $1.58 \mathrm{E}-01$ & 6.73E-01 & 0.000 \\
\hline & Caudate volume & 0.036 & 0.026 & $1.50 \mathrm{E}-01$ & 6.73E-01 & 0.001 \\
\hline & Putamen volume & 0.023 & 0.025 & 3.77E-01 & 7.27E-01 & 0.000 \\
\hline & Thalamus volume & 0.051 & 0.023 & $1.32 \mathrm{E}-02 *$ & $2.52 \mathrm{E}-01$ & 0.002 \\
\hline
\end{tabular}




\begin{tabular}{|c|c|c|c|c|c|c|}
\hline \multirow{10}{*}{ EA (prior= 1$)$} & TBV & 0.134 & 0.025 & $9.65 \mathrm{E}-08 *$ & $1.35 \mathrm{E}-05^{*}$ & 0.017 \\
\hline & Cortical GM & 0.012 & 0.015 & $4.21 \mathrm{E}-01$ & 7.59E-01 & 0.000 \\
\hline & Total WM & -0.015 & 0.014 & 2.92E-01 & 6.73E-01 & 0.000 \\
\hline & Subcortical GM & 0.026 & 0.018 & $1.51 \mathrm{E}-01$ & 6.73E-01 & 0.000 \\
\hline & Total Ventricular volume & 0.031 & 0.028 & 2.72E-01 & 6.73E-01 & 0.000 \\
\hline & Cerebellum volume & 0.044 & 0.023 & 6.02E-02 & 5.16E-01 & 0.001 \\
\hline & Amygdala-hippocampus complex & -0.033 & 0.020 & $1.46 \mathrm{E}-01$ & 6.73E-01 & 0.001 \\
\hline & Caudate volume & 0.037 & 0.026 & 1.37E-01 & 6.73E-01 & 0.001 \\
\hline & Putamen volume & 0.024 & 0.025 & 3.59E-01 & 7.02E-01 & 0.000 \\
\hline & Thalamus volume & 0.052 & 0.023 & $1.12 \mathrm{E}-02 *$ & $2.48 \mathrm{E}-01$ & 0.002 \\
\hline \multirow{10}{*}{ EA (Infinitesimal prior) } & TBV & 0.129 & 0.025 & $2.66 \mathrm{E}-07^{*}$ & $2.79 \mathrm{E}-05^{*}$ & 0.016 \\
\hline & Cortical GM & 0.017 & 0.015 & $2.60 \mathrm{E}-01$ & 6.73E-01 & 0.000 \\
\hline & Total WM & -0.017 & 0.014 & 2.21E-01 & 6.73E-01 & 0.000 \\
\hline & Subcortical GM & 0.031 & 0.018 & $9.51 \mathrm{E}-02$ & 6.23E-01 & 0.001 \\
\hline & Total Ventricular volume & 0.017 & 0.028 & 5.36E-01 & 8.46E-01 & 0.000 \\
\hline & Cerebellum volume & 0.037 & 0.023 & $1.10 \mathrm{E}-01$ & $6.30 \mathrm{E}-01$ & 0.001 \\
\hline & Amygdala-hippocampus complex & -0.034 & 0.020 & 1.32E-01 & 6.73E-01 & 0.001 \\
\hline & Caudate volume & 0.046 & 0.026 & 6.85E-02 & 5.53E-01 & 0.001 \\
\hline & Putamen volume & 0.033 & 0.025 & $1.98 \mathrm{E}-01$ & 6.73E-01 & 0.000 \\
\hline & Thalamus volume & 0.049 & 0.023 & $1.70 \mathrm{E}-02 *$ & 2.92E-01 & 0.002 \\
\hline \multirow{10}{*}{ Intelligence (prior= 0.01) } & TBV & 0.023 & 0.025 & 3.54E-01 & 6.95E-01 & 0.000 \\
\hline & Cortical GM & 0.014 & 0.015 & 3.52E-01 & 6.95E-01 & 0.000 \\
\hline & Total WM & -0.005 & 0.014 & 7.18E-01 & $9.24 \mathrm{E}-01$ & 0.000 \\
\hline & Subcortical GM & 0.023 & 0.018 & 2.04E-01 & 6.73E-01 & 0.000 \\
\hline & Total Ventricular volume & 0.023 & 0.027 & 4.05E-01 & $7.46 \mathrm{E}-01$ & 0.000 \\
\hline & Cerebellum volume & 0.068 & 0.023 & 3.19E-03* & $1.11 \mathrm{E}-01$ & 0.004 \\
\hline & Amygdala-hippocampus complex & 0.002 & 0.020 & 9.23E-01 & $9.98 \mathrm{E}-01$ & 0.000 \\
\hline & Caudate volume & 0.041 & 0.026 & $1.01 \mathrm{E}-01$ & 6.23E-01 & 0.001 \\
\hline & Putamen volume & 0.019 & 0.025 & 4.66E-01 & 7.84E-01 & 0.000 \\
\hline & Thalamus volume & 0.017 & 0.022 & 3.92E-01 & 7.42E-01 & 0.000 \\
\hline \multirow{8}{*}{ Intelligence (prior= 0.05 ) } & TBV & 0.027 & 0.025 & 2.90E-01 & 6.73E-01 & 0.000 \\
\hline & Cortical GM & 0.015 & 0.015 & 3.14E-01 & 6.73E-01 & 0.000 \\
\hline & Total WM & 0.001 & 0.014 & 9.42E-01 & 9.98E-01 & 0.000 \\
\hline & Subcortical GM & 0.019 & 0.018 & 3.04E-01 & 6.73E-01 & 0.000 \\
\hline & Total Ventricular volume & 0.020 & 0.027 & 4.71E-01 & 7.84E-01 & 0.000 \\
\hline & Cerebellum volume & 0.068 & 0.023 & 3.04E-03* & $1.11 \mathrm{E}-01$ & 0.004 \\
\hline & Amygdala-hippocampus complex & 0.016 & 0.020 & 4.60E-01 & 7.84E-01 & 0.000 \\
\hline & Caudate volume & 0.028 & 0.025 & 2.51E-01 & 6.73E-01 & 0.000 \\
\hline
\end{tabular}




\begin{tabular}{|c|c|c|c|c|c|c|}
\hline & Putamen volume & 0.004 & 0.025 & 8.73E-01 & 9.93E-01 & -0.001 \\
\hline & Thalamus volume & 0.004 & 0.022 & 8.39E-01 & $9.66 \mathrm{E}-01$ & 0.000 \\
\hline \multirow{10}{*}{ Intelligence (prior= 0.1) } & TBV & 0.087 & 0.025 & $5.22 \mathrm{E}-04^{*}$ & $2.44 \mathrm{E}-02 *$ & 0.007 \\
\hline & Cortical GM & 0.007 & 0.015 & $6.16 \mathrm{E}-01$ & 8.90E-01 & 0.000 \\
\hline & Total WM & -0.004 & 0.014 & 7.98E-01 & 9.47E-01 & 0.000 \\
\hline & Subcortical GM & 0.004 & 0.018 & 8.31E-01 & $9.64 \mathrm{E}-01$ & 0.000 \\
\hline & Total Ventricular volume & 0.002 & 0.027 & 9.33E-01 & 9.98E-01 & -0.001 \\
\hline & Cerebellum volume & 0.027 & 0.023 & 2.36E-01 & 6.73E-01 & 0.000 \\
\hline & Amygdala-hippocampus complex & 0.026 & 0.020 & 2.39E-01 & 6.73E-01 & 0.000 \\
\hline & Caudate volume & -0.016 & 0.026 & 5.15E-01 & 8.30E-01 & 0.000 \\
\hline & Putamen volume & -0.014 & 0.025 & 5.72E-01 & 8.68E-01 & 0.000 \\
\hline & Thalamus volume & 0.016 & 0.022 & 4.30E-01 & $7.68 \mathrm{E}-01$ & 0.000 \\
\hline \multirow{10}{*}{ Intelligence (prior= 0.5) } & TBV & 0.124 & 0.025 & $6.87 \mathrm{E}-07 *$ & 5.77E-05* & 0.015 \\
\hline & Cortical GM & 0.018 & 0.015 & 2.33E-01 & 6.73E-01 & 0.000 \\
\hline & Total WM & 0.001 & 0.014 & 9.41E-01 & 9.98E-01 & 0.000 \\
\hline & Subcortical GM & 0.031 & 0.018 & 9.38E-02 & 6.23E-01 & 0.001 \\
\hline & Total Ventricular volume & 0.004 & 0.028 & 8.75E-01 & 9.93E-01 & -0.001 \\
\hline & Cerebellum volume & 0.034 & 0.023 & 1.45E-01 & 6.73E-01 & 0.001 \\
\hline & Amygdala-hippocampus complex & 0.030 & 0.020 & 1.77E-01 & 6.73E-01 & 0.000 \\
\hline & Caudate volume & 0.023 & 0.026 & 3.51E-01 & 6.95E-01 & 0.000 \\
\hline & Putamen volume & 0.022 & 0.025 & 3.88E-01 & 7.41E-01 & 0.000 \\
\hline & Thalamus volume & 0.021 & 0.022 & 2.95E-01 & 6.73E-01 & 0.000 \\
\hline \multirow{10}{*}{ Intelligence (prior= 1) } & TBV & 0.121 & 0.025 & $1.32 \mathrm{E}-06^{*}$ & $7.90 \mathrm{E}-05^{*}$ & 0.014 \\
\hline & Cortical GM & 0.015 & 0.015 & 3.13E-01 & 6.73E-01 & 0.000 \\
\hline & Total WM & -0.001 & 0.014 & 9.30E-01 & $9.98 \mathrm{E}-01$ & 0.000 \\
\hline & Subcortical GM & 0.031 & 0.018 & 8.73E-02 & $6.11 \mathrm{E}-01$ & 0.001 \\
\hline & Total Ventricular volume & 0.001 & 0.028 & 9.83E-01 & 9.98E-01 & -0.001 \\
\hline & Cerebellum volume & 0.038 & 0.023 & $1.01 \mathrm{E}-01$ & 6.23E-01 & 0.001 \\
\hline & Amygdala-hippocampus complex & 0.026 & 0.020 & $2.41 \mathrm{E}-01$ & 6.73E-01 & 0.000 \\
\hline & Caudate volume & 0.030 & 0.026 & 2.27E-01 & 6.73E-01 & 0.000 \\
\hline & Putamen volume & 0.020 & 0.025 & 4.46E-01 & 7.78E-01 & 0.000 \\
\hline & Thalamus volume & 0.023 & 0.022 & 2.49E-01 & 6.73E-01 & 0.000 \\
\hline \multirow{5}{*}{ Intelligence (Infinitesimal prior) } & TBV & 0.122 & 0.025 & $1.18 \mathrm{E}-06^{*}$ & 7.90E-05* & 0.014 \\
\hline & Cortical GM & 0.016 & 0.015 & 2.89E-01 & 6.73E-01 & 0.000 \\
\hline & Total WM & 0.002 & 0.014 & $9.05 \mathrm{E}-01$ & $9.98 \mathrm{E}-01$ & 0.000 \\
\hline & Subcortical GM & 0.041 & 0.018 & $2.35 \mathrm{E}-02 *$ & $3.28 \mathrm{E}-01$ & 0.001 \\
\hline & Total Ventricular volume & 0.012 & 0.028 & $6.76 \mathrm{E}-01$ & 9.13E-01 & -0.001 \\
\hline
\end{tabular}




$\begin{array}{llllll}\text { Cerebellum volume } & 0.041 & 0.023 & 7.61 \mathrm{E}-02 & 5.61 \mathrm{E}-01 & 0.001 \\ \text { Amygdala-hippocampus complex } & 0.018 & 0.020 & 4.14 \mathrm{E}-01 & 7.54 \mathrm{E}-01 & 0.000 \\ \text { Caudate volume } & 0.046 & 0.026 & 6.32 \mathrm{E}-02 & 5.21 \mathrm{E}-01 & 0.001 \\ \text { Putamen volume } & 0.026 & 0.025 & 3.09 \mathrm{E}-01 & 6.73 \mathrm{E}-01 & 0.000 \\ \text { Thalamus volume } & 0.031 & 0.022 & 1.24 \mathrm{E}-01 & 6.66 \mathrm{E}-01 & 0.001\end{array}$

Note: $\beta$, standardized coefficient; SE, standardized error; P-uncorr., uncorrected p-value; P-FDR, false discovery rate adjusted p-value; $\Delta$ Adj- $R^{2}$, difference between the adjusted $R^{2}$ of the full model (PGS + covariates) compared to the adjusted $R^{2}$ of the baseline model (only covariates). 
Table S3. Mean and SD for polygenic scores for schizophrenia in the entire sample of participants with EU ancestry, included ( $\mathrm{n}=1139)$ and excluded $(\mathrm{n}=1691)$ in the current study. $P$-value derived from t-test.

\begin{tabular}{lcccc} 
& All EU children & Included & Excluded & $P$-value \\
Prior $=\mathbf{0 . 0 1}$ & $0.65(2.57)$ & $0.74(2.56)$ & $0.59(2.58)$ & 0.127 \\
Prior $=\mathbf{0 . 0 5}$ & $-15.55(0.90)$ & $-15.55(0.87)$ & $-15.55(0.92)$ & 0.973 \\
Prior=0.1 & $-16.91(0.69)$ & $-16.90(0.68)$ & $-16.92(0.70)$ & 0.411 \\
Prior $=\mathbf{0 . 5}$ & $-16.16(0.46)$ & $-16.16(0.45)$ & $-16.16(0.47)$ & 0.832 \\
Prior=1 & $-15.99(0.44)$ & $-15.99(0.43)$ & $-15.99(0.44)$ & 0.911 \\
Infinitesimal prior & $-6.97(0.22)$ & $-6.97(0.22)$ & $-6.97(0.22)$ & 0.885 \\
\hline
\end{tabular}




\section{References}

Delaneau O, Marchini J, Zagury J-F. 2012. A linear complexity phasing method for thousands of genomes. Nat. Methods 9:179-81; doi:10.1038/nmeth.1785.

Demontis D, Walters RK, Martin J, Mattheisen M, Als TD, Agerbo E, et al. 2017. Discovery Of The First Genome-Wide Significant Risk Loci For ADHD. bioRxiv 145581; doi:10.1101/145581.

Howie BN, Donnelly P, Marchini J. 2009. A Flexible and Accurate Genotype Imputation Method for the Next Generation of Genome-Wide Association Studies. N.J. Schorked. PLoS Genet. 5:e1000529; doi:10.1371/journal.pgen.1000529.

Medina-Gomez C, Felix JF, Estrada K, Peters MJ, Herrera L, Kruithof CJ, et al. 2015. Challenges in conducting genome-wide association studies in highly admixed multi-ethnic populations: the Generation R Study. Eur. J. Epidemiol. 30:317-330; doi:10.1007/s10654-015-9998-4.

Okbay A, Beauchamp JP, Alan Fontana M, Lee JJ, Pers TH, Rietveld CA, et al. 2016. Genome-wide association study identifies 74 loci associated with educational attainment.; doi:10.1038/nature17671.

PGC Autism Spectrum Disorders Working Group. 2017. Meta-analysis of GWAS of over 16,000 individuals with autism spectrum disorder highlights a novel locus at 10q24.32 and a significant overlap with schizophrenia. Mol Autism 8:21; doi:10.1186/s13229-017-0137-9137 [pii].

PGC Bipolar Disorder Working Group. 2011. Large-scale genome-wide association analysis of bipolar disorder identifies a new susceptibility locus near ODZ4. Nat Genet 43:977-983; doi:ng.943 [pii]10.1038/ng.943.

PGC Schizophrenia Working Group. 2014. Biological insights from 108 schizophrenia-associated genetic loci.; doi:10.1038/nature13595.

Price AL, Patterson NJ, Plenge RM, Weinblatt ME, Shadick NA, Reich D. 2006. Principal components analysis corrects for stratification in genome-wide association studies. Nat. Genet. 38:904-909; doi:10.1038/ng1847.

Purcell S, Neale B, Todd-Brown K, Thomas L, Ferreira MA, Bender D, et al. 2007. PLINK: a tool set for whole-genome association and population-based linkage analyses. Am J Hum Genet 81:559-575; doi:10.1086/519795.

Ripke S, Neale BM, Corvin A, Walters JTR, Farh KH, Holmans PA, et al. 2014. Biological insights from 108 schizophrenia-associated genetic loci. Nature 511:421-427; doi:10.1038/nature13595.

Savage JE, Jansen PR, Stringer S, Watanabe K, Bryois J, de Leeuw CA, et al. 2018. Genome-wide association meta-analysis in 269,867 individuals identifies new genetic and functional links to intelligence. Nat. Genet. 50:912-919; doi:10.1038/s41588-018-0152-6.

Wray NR, Ripke S, Mattheisen M, Trzaskowski M, Byrne EM, Abdellaoui A, et al. 2018. Genome-wide association analyses identify 44 risk variants and refine the genetic architecture of major depression. Nat. Genet. 50:668-681; doi:10.1038/s41588-018-0090-3. 
